\title{
Explore Knowledge-Sharing Strategy and Evolutionary Mechanism for Integrated Project Team Based on Evolutionary Game Model
}

\author{
Yanchao Du $\mathbb{D}^{\mathrm{D}},{ }^{1}$ Hengyu Zhou $\mathbb{D}^{1},{ }^{1}$ Yongbo Yuan $\mathbb{D}^{\mathrm{D}},{ }^{1}$ and Xiaoxue Liu $\mathbb{D}^{2}$ \\ ${ }^{1}$ Department of Construction Management, Dalian University of Technology, Linggong Road, No. 2, 116024 Dalian, China \\ ${ }^{2}$ School of Economics and Management, Tongji University, Street Address: Zhongtian Building 2005 Room, No. 1063 Siping Road, \\ Yangpu District, Shanghai, China
}

Correspondence should be addressed to Yongbo Yuan; yongbo@dlut.edu.cn

Received 1 March 2019; Revised 22 May 2019; Accepted 11 June 2019; Published 27 June 2019

Academic Editor: Bo Xia

Copyright (c) 2019 Yanchao Du et al. This is an open access article distributed under the Creative Commons Attribution License, which permits unrestricted use, distribution, and reproduction in any medium, provided the original work is properly cited.

Integrated Project Delivery (IPD) has become increasingly popular in the architecture, engineering, and construction industries. However, the current practice status by the construction industry fails to deliver the desired results. In that backdrop, how to promote cooperation within and improve the overall performance of integrated project team has received wide attention. Herein, knowledge-sharing plays a critical role in cooperation and overall performance. However, to the best of our knowledge, the research on knowledge-sharing strategy interaction and evolutionary mechanism is rare. To make up for the deficiency of the studies existing, a novel model is proposed by taking advantage of evolutionary game theory, to capture the interaction behavior of knowledge-sharing and explore its evolutionary mechanism. Six parameters of knowledge stock, knowledge-sharing degree, heterogeneous knowledge proportion, synergy effect, knowledge absorption coefficient, and knowledge-sharing cost efficient that are critical to knowledge-sharing are extracted and defined. The payoff matrix is constructed by analyzing the benefits and costs of knowledge-sharing. Then, a replicator dynamic system is established based on payoff matrix, to determine the evolutionary tendency of knowledge-sharing behavior. Finally, numerical simulations are conducted to explore the influences of all parameters on the knowledge-sharing strategy. The findings in this research reveal that strategy interaction behavior is significantly influenced by proportion of strategy of choosing to share knowledge in both game players. The authors also find that strategy interaction behavior has a strong negative correlation with knowledge-sharing cost efficient, but has a positive correlation with knowledge stock, heterogeneous knowledge proportion, degree of knowledge-sharing, knowledge absorption coefficient, and synergetic effect coefficient. This research can provide the evolutionary mechanism and broaden our understanding of relationship between project performance and knowledge-sharing and can offer valuable guidance on improving cooperation and performance of project teams.

\section{Introduction}

Since the 1970s, the global and the Chinese construction industry have been flourishing. New project delivery approaches such as design-bid-build (DBB), design-build (DB), and construction management at risk (CMR) have been constantly springing up [1], which are widely applied and popularized in practice. However, productivity has not been improved dramatically, and it is hard to satisfy the stakeholders' performance expectations [2]. According to an industry report published by Construction Management Association of America (CMAA), 30\% of construction projects are over the schedule or exceed budget. In fact, nonvalue-added activities done by the traditional project team assume most of the time in the construction process [3]. Researchers recommend that a better collaborative and coordinated project delivery method should be developed to overcome these drawbacks [4].

Integrated project delivery (IPD) has been recognized as a new delivery method integrating people, systems, business 
structures, and practices into a single process, wherein project participants, including the owner, designer, general contractor, and special subcontractor, can work collaboratively at the early design stage. IPD increases values to the owner, decreases waste, and maximizes project benefits by utilizing multiparty contract to share benefits and risks. However, according to the investigation carried by Kelly [5], the project performance that adopted the integrated project delivery approach did not achieve desired results in practice. One of the significant reasons is that the cooperative behavior among integrated project team members is hampered to some extent, thereby leading to an overall performance decline. The failure in performance improvements thus makes it imperative for research to address this issue in order to effectively facilitate better cooperation.

In a knowledge-based economic society, organizational or a project team competitiveness arise from intangible rather than tangible resources [6]. In this economic context, knowledge is defined as the skills, objectives, and experiences that together create a framework, for assessing and making use of information exchanged in an explicit or implicit manner [7]. Most researchers have argued that the competitiveness of an organization relies on the ability to create valuable knowledge and share it with all project team members within this organization, in order to infuse this knowledge into products, services, and systems [8]. Thus, a successful knowledge-sharing strategy requires effective cooperative relationships among integrated project team members. This is critical for facilitating cooperation and project performance [9]. Without high-level knowledgesharing, a project team leader becomes unable to integrate all the advantages that stakeholders offer (e.g., rich experience, strong organization management skills, and informationprocessing capability), for efficiently and effectively executing large and complex projects [10].

Cooperation is a common phenomenon in nature and human society. It is called the third evolutionary principle besides selection and mutation. As an internal driving force of species evolution and social development, it promotes the formation of complex life systems and social organizations. From the perspective of individual survival and development, cooperative behaviors will reduce their own benefits and weaken their competitive advantages. From the perspective of society or team development, cooperative behavior is beneficial to the overall interest, although it may reduce individual interest. In construction industry, the best practice is to realize the overall performance and balance individual benefit. In traditional project deliveries, implementation process is poorly integrated and information is asymmetric, and the first consideration of each participant is not to maximize the benefits of the overall project, but to maximize individual interest and avoid risks, which usually leads to an overall project significant loss. Hence, it is essential to adopt the idea of IPD to solve this dilemma. To this end, we should first capture the dynamic behavior of being cooperative and make clear how cooperative behavior spreads and maintains stability in an IPD team, namely, evolutionary mechanism, from the perspective of knowledge-sharing to provide theoretical foundation for controlling and optimizing cooperative behavior in an IPD team.

In the construction industry, the best practice is to realize the overall performance while balancing individual benefits. The implementation process in traditional project delivery is poorly integrated, and crucial information is asymmetric. Often, each participant does not prioritize maximization of the project's benefits. Instead, she or he chooses to maximize individual interest and avoid risk, leading to significant project losses. These counterproductive behaviors make it necessary to adopt IPD as a solution. To this end, we first capture the dynamic behavior of cooperation and clarify how cooperative behaviors spread within and support the stability of an IPD team; that is, we identify the evolutionary mechanism. We then adopt the perspective of knowledge-sharing to provide a theoretical foundation for controlling and optimizing cooperative behaviors in the IPD team.

Despite the importance of knowledge-sharing in cooperative behaviors of the integrated project team, very few studies have focused on improving cooperation from this perspective to explain the dynamics of group behavior and how cooperative behavior spreads and maintains stability in the integrated project team, namely, evolutionary mechanism. Therefore, our goal is to explore knowledge-sharing strategies and reveal the evolutionary mechanism that underpins the integrated project team. We analyze the resulting evolutionary tendency along with the variations in relevant factors.

Our study contributes to both theory and practice. First, we propose an intrinsic evolutionary mechanism for knowledge-sharing strategies. Second, we provide valuable references for integrated project team leaders to broaden their understanding of how cooperation is influenced by different factors, which would allow them to take corresponding measures to improve team performance.

The remaining paper is organized as follows. In Section 2, we present the systematic overview of the extent literature on IPD approaches and knowledge-sharing. In Section 3, we explore the reasons for employing evolutionary game model. In Section 4, we propose a novel evolutionary game model to capture the dynamic behavior of knowledge-sharing. In Section 5, we conduct numerical simulations to validate our results of theoretical analysis and discuss the influences of model parameters on the evolutionary tendency of the interaction behavior. In the last section, we conclude the paper and present the implication of our work.

\section{Literature Review}

2.1. Integrated Project Delivery. Compared with other industries, the architecture, engineering, and construction (AEC) industry lacks a reliable reputation as a leading actor in quality, productivity, and time and cost management because of its increasing complexity and multidisciplinary nature. Most researchers have claimed that the project success largely depends on the complexity of a project, which then directly influences the overall project performance [11]. Therefore, it is important to recognize this feature. Gidado 
[12] analyzed project complexity from two aspects: (1) the managerial, which is related to new workflow reengineering and building information technology, and (2) the technological, which is related to the technological complexity of implementing a single work. The results showed that the managerial style and information technology of traditional project delivery cannot satisfy the requirements of cost control, quality improvement, and schedule optimization due to complexity of construction project. The construction industry calls for a renewed project delivery approach to further improve the overall project performance. Given these requirements, many scholars and practitioners have begun to focus on the project complexity, including the managerial and technological. This gave rise to IPD and building information modeling (BIM).

IPD encourages key stakeholders to collaborate as an integrated project team to maximize project benefits. It is similar in the function to the Japanese Toyota production system [13]. An IPD prototype was first applied in BP oil drilling platform, achieving limited success through project alliance [14]. Soon afterward, this approach was introduced into the Wandoo Project, and East Spar Project in Australia and the Comprehensive Medical Project in California. In both cases, it boosted productivity and project performance [15]. Since then, IPD has received more attention from experts and practitioners in AEC industry. In order to promote the application of IPD, Consensus DOCS, an alliancing institute founded by 22 leading engineering associations, published a series of contracts to guide the implementation of integrated project delivery. IPD is distinct from traditional delivery in the following ways [16]: (1) all key stakeholder participating in the early design phase; (2) all key stakeholders signing multiparty relationship agreements; (3) a sharing mechanism for benefits and risks exists; (4) there is collaborative decision-making and integrated target control; and (5) all key stakeholders are subject to liability waivers. The American Institute of Architects (AIA) also asserts some benefits if those principles mentioned above can be executed by the key participants, which include the following:

(i) Reduce or eliminate conflicts that often occur in the traditional project team

(ii) Control risk effectively among key participants

(iii) Facilitate cooperative relationships among integrated project team members

(iv) Shorten the project development period from design to handover

(v) Decrease requests for interpretation sent by the prime contractor and subcontractor

(vi) Reduce waste by better and comprehensive schedule

(vii) Contribute to employing cutting-edge technology such as BIM

(viii) Enhance knowledge-sharing in the integrated project team

(ix) Reduce project management cost (x) Improve project quality through better construction management

Investing the Orlando Utilities Commission North Plan project, Matthews and Howell [17] found 10\% cost savings below the $\$ 6$ million GMP owing to the collaboration in the integrated team. Coincidentally, a report published in the 2006 AIA integrated practice conference emphasized the achievement of 40 Australian projects owing to a project alliance (PA) that based on IPD principles. The AIA cooperated with University of Minnesota to investigate 12 large and complex IPD projects. They concluded that the projects, despite challenges in the implementation process, still satisfied the requirements of an aggressive schedule and budget goals [18].

Despite the emergence of IPD as an advanced delivery approach, the extent literature has reported some obstacles in its practices, including lack of specific tools for its implementation, poor communication protocols, information barriers, weak benefits distribution, and insufficiently trust-based relationship. This has prevented IPD from being employed on a large scale $[19,20]$. AIA, as a forerunner in IPD, has acknowledged that these barriers and challenges form the concept of IPD to field application. Legal and financial issues, including liability and risk-sharing, were identified; active and stronger collaboration can be accomplished through contractual and organizational. Most recently, to overcome IPD dependence on "big room" collaboration requiring all stakeholders to be present all the time, Ma et al. [21] set up a collaboration platform for IPD team. The results showed that the dedicated platform can significantly reduce the difficulty associated with IPD implementation and thus prompt knowledge transfer between project team members. However, it lacks analysis on how to integrate scatted and heterogeneous information from project team members and does not consider the influence of information sharing mechanism on the architecture of platform. IPD, as a delivery method, introduces BIM as a forceful technology tool. With a growing trend toward the application of building information model (BIM) technology in large and complex projects, an increasing number of experts have paid great attention to investigate the influence on project performance with the utilization of BIM and IPD. Using structural equation modeling (SEM) to explore the questionnaire responses of more than 100 BIMenabled projects, Chang et al. [22] demonstrated that the acceptability of IPD can be influenced positively. All key participants in a project team can exchange design and construction information to reduce waste and change orders on the BIM platform [23]. BIM technology is perfectly suitable to acts as a powerful tool for the integrated project teams [16]. Moreover, the influence of organizational culture on integrated project teams will be effective once BIM is implemented. As for this question, Howard contended that BIM services offered to IPD will facilitate collaboration in integrated project teams, making the project goal's link to reality clearer [24].

Researchers have analyzed the performance of traditional project delivery systems. Indeed, there is increasing 
proof that a delivery method with high-level collaboration yields better performance than a delivery method with lowlevel collaboration. However, the AEC industry has not fully exploited the potential value of integrated project delivery system. For example, although $84 \%$ of AIA members learn about the concept of IPD, less than $40 \%$ have a deeper understanding of it, and only $13 \%$ have executed it [25]. The efficiency and effectiveness of project performance not only depend on the quantity, but also the quality, of knowledgesharing interactions between team members. Therefore, it is essential to promote collaboration for IPD team from the perspective of knowledge-sharing.

\subsection{Knowledge and Knowledge-Sharing}

2.2.1. Knowledge. Knowledge is regarded as a key factor in favor of enhancing competitive advantage for organization and project team [26]. Organization and project team with a lot of valuable knowledge are expected to achieve outstandingly [19]. Importantly, it has replaced traditional resources, such as capital and labor, as the most important resource in construction [20]. Polanyi [27] divided knowledge into two types, namely, explicit and tacit. The former refers to knowledge that can be transmitted by a database, photograph, or mathematic formula via computer programming technology. On the other hand, the latter derives from individual observations and perception of experience, expertise, insights, and talents, none of which can be depicted accurately [28]. Since then, many scholars have followed such a division and studied explicit knowledge and tacit knowledge, respectively, in many fields like education, psychology, project management, information management, and so on [29]. Hansen et al. [30] divided knowledge within an organization into two forms: codification and personalization. Codification refers to the organization converting personal knowledge into the form of explicit knowledge. In this approach, two coding systems of knowledge-sharing are presented, herein: workflow and database. The organization encodes knowledge into workflow and information flow for easy use by all team members. Personalization, which is usually used to solve strategic and low-repeatability problems, refers to connecting members who do not possess kinds of knowledge with the members who do possess it in the form of person-person or person-linkage-person. Project team members always hope to obtain the tacit knowledge owned by the seasoned experts for improving personal ability and skills. However, such knowledge must be transformed into explicit knowledge first, which is also a subject of academic investigation. Couchman and Fulop [31] took advantage of the nature language processing technology to analyze records and documents provided by enterprises. They thus proposed a framework to extract tacit knowledge, wherein their results revealed that tacit knowledge can be translated into explicit knowledge more efficiently using this framework. Nonaka [32] critiqued this approach, stating that the authors focused more on accessing and acquiring explicit knowledge while this knowledge only accounts for only a small portion of all possible knowledge. However, Wu et al. [33] proposed a different viewpoint: that is to say, explicit knowledge is one of the most important resources to promote project performance when considering rapid development of image identification technology. It is believed that a dispute regarding which type of knowledge is more valuable would likely miss the essence of the question, without factoring in knowledge-sharing. In fact, both tacit and explicit knowledge are mutually dependent; they collectively strengthen the significance of knowledge: tacit knowledge constitutes the background required for specifying the structure to exploit and explain the explicit knowledge. Therefore, we do not distinguish the two concepts, but treat them as a whole, namely, knowledge.

2.2.2. Knowledge-Sharing. Knowledge-sharing is generally implemented through various channels within or across an organization in the form of documentation, databases, communication, and group discussion [34]. It is a complex process that involves knowledge collection, absorption, and transformation; it is considered critical to improve team flexibility [35]. Issa and Haddad [36] claimed that knowledge-sharing, as a significant component of knowledge management, reflects the provision or receipt of work information, skills, and feedback with respect to a product [37]. Navimipour and Charband [38] believed that knowledge-sharing plays an important role in a project team, because it offers a link between the member and the project team by cutting down cost and enhancing the project performance. The authors conducted a comprehensive and systematic review of the knowledge-sharing mechanism by screening 28 out of 71 papers identified. According to the findings, knowledge-sharing, mutually benefitting relationship, sense of self-worth, and external motivation are crucial factors of an academician's opinion towards knowledge-sharing, and work efficiency, innovation, and organizational learning can be impacted positively by knowledge-sharing. Moreover, the authors also found that when a trust-based relationship is established among team members, knowledge-sharing behavior occurs more quickly. However, they neglected to monitor the influence of absorption capability on the effect of knowledge-sharing owing to limited resources from data bases. Annadatha [39] examined social-cultural factors such as trust, shared goals, close relationship, and shared language as important factors toward knowledge-sharing in a virtual project team by social network analysis approach. The results showed that trust, close relationship, and language importantly affect the outcome of knowledge-sharing, while shared goals do not have significant impact on knowledge-sharing. However, as an important social-cultural factor, knowledge-sharing willingness is not checked. Farajpour [40] further developed a four-leveled hierarchical inference system, which is composed of six fuzzy rule bases, to evaluate the information degree in the supply chain. The results showed that the information sharing degree is influenced by willingness importantly. However, this research does not address how willingness affects information sharing behavior dynamically from theoretical foundation perspective. 
Khatri et al. [41] pointed out that the team members should assist coworkers in realizing their potential and going beyond their limitations; in that context, the trust relationships between team members would be generated and they are inclined to share knowledge with each other [42]; however, they did not distinguish between the types of knowledge, such as heterogeneous knowledge or common knowledge. Further, Yuan et al. [43] found that project commitment directly influenced explicit knowledge-sharing and mutual trust; however, its influence on tacit knowledgesharing was absent. Zhang and He [44] conducted asystematic literature review, to detect 31 factors influencing implicit-knowledge-sharing in an IPD team by using a questionnaire. They collected data from 300 respondents, to the factors influencing implicit-knowledge-sharing importantly through significant analysis. Subsequently, factor analysis was adopted to gather the similar factors, such as swift trust (ST), personal benefits (PBs), lack of self-efficiency (LSE), identification-based trust (IBT), and information-based trust (INBT). The authors later made use of path analysis to analyze the interrelationship between these five critical factors and their influence on implicit-knowledge-sharing. The factor analysis revealed that $\mathrm{PB}$ is positively correlated with ST and IBT. IBT can shorten selfefficiency, which affects tacit knowledge-sharing negatively. This study displayed a deep analysis of what sort of trust impacts implicit-knowledge-sharing, besides making clear the close relationship between trust and implicit-knowledgesharing. It also found that ST influences INBT and IBT importantly, which in turn is positively correlated with implicit-knowledge-sharing. However, the authors did not consider the influence of knowledge stock on tacit knowledge-sharing behavior.

Zareie et al. [45] investigated the influence of electronic environment knowledge (EEK) on the environment behavior (EB) by collecting data from 330 students. The author established a structural model of the key factors affecting environment behavior. Subsequently, the model was validated using the smart PLS 2.0. The results proved that EEK influenced the EB directly in education. Later, the author studied the relationship of e-learning system between the employee's commitments with the same method. The results showed that employee's commitments are positively and crucially affected by learner's satisfaction, readily available training material, personalized autonomous learning, and work efficiency and subsequently positively relate to the employee's competitive advantage [6]. Further, learners' or employee's satisfaction was positively and vitally influenced by technology, education content, motivation, and attitude [46]. Then, a comprehensive literature review on knowledgesharing mechanism in education was conducted by Charband and Navimipour [47], revealing how competitive capability, creativity, learning effect, and interaction behavior can be enhanced or optimized by knowledge-sharing. However, whether the findings can be applied to the constructions industry is doubtful, because the knowledgesharing mechanism in the education field has a great difference from construction project team, especially for an integrated project team. First, educational organizations are mostly nonprofit, while the construction project team operates for profit. Moreover, projects are established to only complete a specific project task, after which the project teams are dissolved; that is to say, they are temporary. In construction, the composition of the project team members is not immutable, but constantly adjusted as the project progresses or changes. Hence, the project team is characterized by openness. The project team also often consists of members with different majors and experiences, and the construction project is comprehensive complex. Finally, such projects have a significant constraint of quality, duration, cost, environment, capital management, technology, safety, and other objectives.

An important development in knowledge-sharing has been the growth of cloud computing. In order to enable cloud, users acquire necessary human expertise at any location and share their own experience and knowledge in the cloud. Navimipour et al. [9] proposed an expert cloud-based framework, and in their study, this system enhanced the organization's performance and customer satisfaction. However, the findings did not consider human resources in different regional contexts. Whether these findings can be generalized requires further investigations. Later, regarding architectural problems and component analysis of expert clouds, Navimipour et al. [48] used NuSMV model checker, Argo UML, and Rebeca Verifier tools to extract the checking attributes in the form of LTL and CTL formulas of control behaviors and validate the attributes automatically, and the results indicated that the system was reliable. However the layers and related components still need to be improved in the future, and the algorithm needs to be developed for the whole components, not only the specified properties of controlled behavior. Subsequently, Fouladi and Navimipour [49] proposed a cloud-based knowledge-sharing framework utilizing the quality control (QC) criteria. The authors used these criteria of QC to develop a ranking diagram of human resources on basis of trust, reputation, cost, and expertise, which is offered for members to choose the required human resources. To rank the human resources in the expert cloud, an AHP-based method was introduced to assign weights to features, by especially considering the interdependence among features. The authors found that compared with the previous studies, a hierarchical structure improved the quality and speed rating of human resources. However, dynamic and interactive nature of the relationship variables in the cloud was not captured. According to the description of researches above, we know that these researches on the knowledge-sharing so far mainly focused on the technology and assessment mechanism perspective than the theoretical level to explore knowledge-sharing behaviors in the project team.

Knowledge-sharing behavior within a project team does not occur spontaneously. Knowledge-sharing not only has economic benefit, but also has social relationship benefit [50]. Appropriate reward or motivation is believed to play an important role in knowledge-sharing. Further, the social exchange and social capital theories highlight that organizational rewards such as promotion, bonus, and high salary can promote knowledge contribution with greater frequency 
in the knowledge management system [51]. However, lack of sufficient benefits is one of the most important reasons hindering knowledge-sharing in the information context, so it is critical to design a perfect incentive mechanism to promote it [52]. Gupta and Govindarajan [53] sated that a challenging rewards system should be developed to encourage employees to participate in sharing activities by learning it from the case of Nucor Steel. However, it only offered the suggestions according to results extracted from the practice perspective, with no theoretical analysis of the operational mechanism of cost of knowledge-sharing behavior. Jewels [54] studied the why the individuals serving in IT project teams are easily motivated to or suppressed towards participating in sharing expertise. The key findings revealed that an individual's inclination to share expertise and skills with others is a function of the associated benefits and costs. However, how the function of benefits and cost acts on the knowledge-sharing behavior is not discussed. By analyzing the benefits and cost of knowledge-sharing between a traditional pyramid organization structure and a networked enterprise structure, Liu [55] maintained that it is necessary for enterprises to flatten the organizational structure in order to improve coordination among team members. However, while direct benefits were considered here, the potential impact of the synergy benefit from the coordination among project team members was not. Navimipour and Soltani [56] then investigated the influence of key factors, including cost, technology acceptance, and satisfaction of employee, on the effectiveness of electronic customer relationship management (E-RCM) by establishing SEM, and it was tested, based on questionnaire data collected. The results indicated that the effectiveness of E-RCM is affected positively by customer cost. However, the cross-sectional data were collected at a single point of time, and hence, they cannot dynamically capture the relationships among influence factors at a different stage. According to aforementioned researches, we can conclude that benefits and cost affect the behavior of knowledge-sharing greatly. However, these literatures describe the benefit and cost only as a total concept, respectively, while exploring the knowledge-sharing behavior statically from macro aspects.

Recently, with the increase of project scale, complexity, and dynamic property in AEC industry, more and more team leaders across modern project organizations are seeking the way to master and thus make advantage of the enormous multidisciplinary knowledge [19]. Organizations in the AEC industry presents apparent knowledge-intensive characteristic, highly depending on the rich knowledge stock and expertise derived from project team members [57, 58]. Based on the data collected from the respondents, Cooke [59] made use of structural equation modeling to study the relationship between knowledge-sharing and project complexity. The results showed that knowledge-sharing can mitigate the impact of project complexity. Ribeiro [60] also proposed the similar point of view that project team members in the AEC organizations need to actively share knowledge and expertise to deal with complicated and difficult tasks. Xia and Chan [61] argued that the construction complexity affects the success of a project and developed a composite complexity index for measuring the construction complexity through tapping expert knowledge in construction field and thus help stakeholders and constructors take appropriate actions to improve the project performance. Owning to the importance of knowledgesharing behavior, organization leaders should be conscious of the tremendous advantages brought by knowledgesharing behavior [62] and try to study the measures that can improve the project performance from the perspective of project team members [34]. China, as the largest engineering construction country in the world, has many buildings and infrastructures in progress. A vast amount of knowledge can be repeatedly applied to different types of construction projects, despite the unique disposable characteristic of the construction project [63]. The construction management organizations, with the temporary feature, easily lead to plenty of knowledge loss, when project teams are disbanded. Therefore, it is necessary for stakeholders to share their own valuable knowledge with other stakeholders in the project team to avoid the "reinvention of the wheel" in the other new projects [64].

The systematic review of the extant literature reveals that, with the emergence of large and complex engineering projects, the "loose" collaboration pattern under tradition delivery has not been able to meet the needs of efficient project management. On the other hand, the IPD approach, based on the lean construction theory, becomes the research focus of the construction industry. Most researchers have recognized the importance of knowledge-sharing to project teams and presented its effectiveness to improve project performance. However, few have focused on the selection strategies of knowledge-sharing and thus explored how these strategies change dynamically over time in the IPD team. Therefore, the objective our objective is to capture the interaction behavior of knowledge-sharing among IPD team members and explore its evolutionary tendency associated with respect to influence factors.

\section{Research Method}

Cooperative and competitive relationships exist among integrated project team members. Whether or not the project team members choose to share knowledge is a complicated and dynamic game process. Therefore, to explore the knowledge-sharing strategy and evolutionary mechanism for IPD team, the most important work is to develop an algorithm that can capture dynamically the strategy interaction behavior. Currently, according to the available studies, the methods to focus on knowledgesharing mechanism, such as SEM, case study, classic game theory, and social network analysis that we will analyze, respectively, in the following, can merely capture the static strategy interaction behavior at a point of time, which cannot predict the knowledge-sharing behavior evolutionary trend over time. Leveraging the evolutionary game theory to study knowledge-sharing is helpful to dynamically analyze the process of strategy selection from the micro perspective.

SEM is a method capable of measuring the underlying latent constructs identified by factor analysis and assessing 
the path of the hypothesized relationships between the constructs to address the complicated behavioral relationships [65]. However, while SEM has been popular for its advantages, it had been criticized for incredible conclusion owning to its indiscriminate utilization [66]. Also, Cliff [67] questioned the improper use of SEM and pointed out its potential drawbacks. First of all, the data obtained by researchers cannot completely confirm or deny the correctness of a model, because the model is artificial and can be redefined in many ways. Next, chronological evidence does not represent cause and effect, and the naming of latent variables is a subjective process other than an objective fact, quite apart from the trap of nominalistic fallacy existing in the estimation of latent variables. Furthermore, the researchers may unconsciously apply excessive modification programming in the model for obtaining the ideal model, namely, overfitting problem, which is really hard to control in data processing, leading to larger distortions between results and the real situation [68]. Recently, Xiong et al. [69] analyzed the limitations and risks in SEM applications through systematic literature review of 84 articles in solving construction research problem and found that sample size, goodness of fit measures, and especially construct validity are significant problems need to address. Although a guideline framework is given to solve these issues, however, the substantial weakness that it only reflects statically a situation at a point of time and is unable to capture the dynamic interaction behavior cannot be solved.

Due to the number of variables processed by SEM and the complex relationships among variables, a large sample size must be used to maintain an unviolated statistical hypothesis. Therefore, the influence of sample size is important issue for SEM. Breckler [70] conducted an analysis of 72 SEM empirical studies in the field of personality and social psychological. The sample size is between 40 and 8,650, with a median of 198 . One-fourth of the studies has a sample size smaller than 500 , while $20 \%$ had smaller than 100 . The author concluded that a sample size larger than 200 can be regarded as a medium-sized sample, while that below 200 is discouraged when pursuing stable SEM results. Consequently, reliable results are impossible with a small sample size, besides the overfitting problem, which is hard to control. Such SEM drawbacks can easily lead to faulty conclusions. In fact, SEM is mainly suitable for research on the relationships among constructs from macro perspective [71] and cannot explore the mechanism of action of the constructs from the inner nature of things. However, the novel evolutionary game model we proposed can avoid this dilemma, because it can simulate IPD team member strategy interaction behaviors determined by the key factors. This is done by setting sufficient units representing the sample size of the team members. In other words, the sample size does not affect this method.

Some researchers, for example, Yoo [72] and Annadatha [39], also use case study and social networks analysis, respectively, to investigate the knowledge-sharing mechanism among project team members. The case study is an effective approach to provide empirical evidence indicating how key factors affect the outcome of knowledge-sharing behavior
[73]. However, it can only reflect the external phenomenon, but not the internal mechanism. Further, social network analysis emphasizes interpersonal relationship, relationship connotation, social network structure, and social phenomenon, which can assist in regulating the project team and identify knowledge-sharing barriers [74]. However, this type of analysis also cannot determine the dynamic variation trend of knowledge-sharing behavior.

Classic game theory is often used by some scholars in knowledge-sharing mechanism, for example, Luo and Yin [75]. This theory was initially exploited to analyze strategic interactions in the economic sphere. It has been frequently applied in similar fields over the past decades, with encouraging achievements [76]. In most researches, to confirm the model prediction to theoretical analysis, the classic game theory assumes that the game players should exhibit highlevel rationality and possess complete information of the other game players. Further, mistakes are not allowed throughout the game process [77]. However, this extremely strict assumption cannot be satisfied in most cases, because it is nearly impossible for each game player to be entirely aware of the complete information on competitors [78]. Additionally, the decision-making is also influenced significantly by the knowledge level of the game player. In fact, the game players, who are limited by rationality, often make dynamic changes to the strategies by comparing the payoff with other competitors [79]. Hence, the assumption of super rationality limits the application of Classic game theory.

To solve this problem mentioned above, the evolutionary game theory was developed by replacing high-level rationality with bounded rationality assumption allowing information incompleteness and asymmetry [80]. This theory deals with the emergence, transformation, diffusion, and stabilization of behavior forms. It integrates the idea of evolutionary biology and rational economics, combining game analysis with evolutionary dynamics, to provide a powerful analytical tool for the study of the cooperative behaviors, and a replicator system, as the core of the evolutionary system, is utilized to express the evolution mechanism of the game players [81]. This characteristic of the evolutionary game theory effectively explains the behavior of long-term economic and transaction relations among large populations well. So far, economists and sociologists have made remarkable achievements by employing evolutionary game theory to analyze the factors that influence the formation of social habits and social system, and it has been used to explain the process of formation [82].

According to a previous description, the most important finding obtained is that evolutionary game theory is a suitable method with the characteristics to predict the evolutionary trend of strategy interaction behaviors, and consequently, based on its unique advantage, we propose a novel evolutionary game model to study the knowledgesharing strategies and the evolutionary mechanism.

\section{Evolutionary Game Model}

4.1. Model Parameters. Based on a comprehensive and systematic literature review, we can identify that the factors of knowledge stock, degree of knowledge-sharing, 
heterogeneous knowledge, synergy effect, knowledge absorption capability, and cost control capability of knowledge-sharing have been rarely studied systematically in knowledge-sharing fields. However, these factors play a critical role in affecting the cooperative behavior. Hence, the following model variables are presented based on critical analysis as follows:

$K_{i}$ : knowledge stock refers to the total amount of knowledge of an organization, which reflects its competitiveness and potential to deal with tasks. Researchers have different points of view on knowledge, but reach a broad consensus. Knowledge is a necessary and sustainable resource and has become the most important element in all walks of life [52]. In this study, we hold that the definition of knowledge should be developed not only according to economic significance, but also easy operability, observability, and measurability. A successful organization or enterprise in the construction industry can always create and spread knowledge among project team members and eventually embody this knowledge in products and services [83]. The traditional project management system based on capital and labor can no longer effectively explain the phenomenon of performance improvement of the project team [84]. Knowledge as a resource, like other capital, can be produced and exchanged. Its accumulation is a prerequisite for successful project management. However, how to preserve knowledge and make use of knowledge resources created by project team members are challenges we face at present, which involves concept of knowledge stock. We thus introduce it as a parameter into the evolutionary game model.

$\eta_{i}$ : degree of knowledge-sharing refers to willingness to share the knowledge provider in the integrated project team. The stronger the willingness to share, the higher the degree of knowledge-sharing. The willingness to share knowledge mainly reflects the extent to which the project team members are inclined to share and provide relevant knowledge and experience with the other team members through various ways and activities in the workplace [85]. According to the social cognition theory [86], behavior can be best explained by the continuous interaction between cognition and environmental factors. In order to achieve a sense of achievement in work, strong intrinsic motivation plays an important role in triggering the willingness to share $[87,88]$. Intrinsic motivation refers to the satisfaction brought by team members towards the work. It is derived from the participants' strong pursuit and willingness to challenge the work. Team members with intrinsic motivation are curious and enthusiastic about their work and they tend to explore unusual solutions spontaneously and actively. Such behaviors indicate that these project team members can show a high level of creativity $[89,90]$. However, only depending on intrinsic motivation to improve the degree of knowledgesharing is not sufficient. Without trust-based business relationship and rewards, the effect of willingness will be undermined [91]. Hence, we can find that the degree of knowledge-sharing is affected by three factors including intrinsic motivation, trust-based relationship, and incentive mechanism. The extant literature has rarely focused on the relationships between the willingness and knowledgesharing. In this paper, we deliberately introduce degree of knowledge-sharing as a parameter in the evolutionary game model to fill this knowledge gaps.

$u_{i}$ : Heterogeneous knowledge proportion, $u_{i}$, refers to the ratio of the amount of complementary knowledge to the amount of shared knowledge. The larger the heterogeneous knowledge proportion, the stronger the complementarity. Shi et al. [92] divided knowledge into complementary and homogeneous knowledge types according to the similarity of the knowledge structure. The former is the inherent attribute of knowledge. It is the core knowledge that team members distinguish from the others and can bring competitive advantages for team members [93, 94]. The project organization exists as a system and comprises smaller subsystems. According to system theory, the components within the system are interrelated. It is this close connection that allows the personnel to consider the system as a whole, while paying attention to the interaction behaviors among its distinct parts. Traditionally, in order to improve labor efficiency, organizations are operated through strict division of labor. However, strict specialization not only improves labor efficiency of workers, but also disrupts internal connection. While managers do help coordinate, the overall organizational efficiency declines due to the tacit feature of knowledge and information distortion that occur during transmission. That is true especially when it comes to the utilization and innovation of knowledge [95]. Specialization has its limitations, and specialization itself is subject to diminishing returns. Overspecialization leads to losses because the division of labor and knowledge must be coordinated, wherein the latter requires coordination because they are complementary.

For an enterprise or organization, knowledge complementarity could increase returns, because the fusion of discrete and complementary knowledge can bring about innovation, possibly leading to cost reduction, quality improvement, and profit increase [96]. This is particularly important in the information economy where knowledge assets are increasingly replacing physical assets. Hence, heterogeneous knowledge is an important parameter that we introduce into the evolutionary game model.

$\beta_{i}$ : Synergy effect coefficient, $\beta_{i}$, refers to the knowledgesharing effect that reflects the capability of integrating the complementary knowledge existing among different project team members. It is originally a physical and chemical phenomenon, wherein, when two or more components are added or mixed together, the resulting effect is greater than the sum of the various components when utilized alone. That is, " $1+1>2$ ". Ever since the concept of synergy effect was introduced into the field of enterprise management, it has been become an important element of enterprise or organization for efficiency improvement. The synergy effect is divided into four types: sales, operation, investment, and management synergies. On the other hand, Chen and Liu [97] divided it into five types from the perspective of enterprise resources: strategic, cultural, human resource, supply chain, and financial synergies. While difference exists between two classification methods, they both proved that 
synergy effect is important to increase the benefits to participants in collaboration. The extant literature has revealed that the knowledge synergy between organizations is complex and not a simple linear manner in knowledge transfer. In this study, based on the emergency theory of partner selection, combined with the research of Montoya et al. and Zeng et al. [98, 99], and the management practice derived from Chinese enterprise, we take into consideration the influence on the synergetic effect coefficient from the perspective of synergy management system including cultural synergy, technical synergy, and organization synergy. The synergetic effect is an important factor influencing the project performance, thereby enabling it as a parameter in the evolutionary game model.

$\alpha_{i}$ : Knowledge absorption coefficient, $\alpha_{i}$, refers to the capability of knowledge receivers to assimilate the knowledge that transmitted by the knowledge providers and convert it into their own competitive knowledge. This plays an important role in improving the knowledge-sharing benefit of the knowledge provider. The higher the knowledge absorption coefficient, the higher the capability of assimilating knowledge. The absorptive capacity theory argues that the knowledge absorptive capacity is the ability of an individual or organization to identify the value of new outside information, and then absorb and apply it for a specific business purpose. The individual knowledge absorptive capability determines whether knowledge receiver can update their own knowledge system in a timely and accurate manner [100]. Thus, it can be inferred that the innovation performance of project team members is closely related to individual knowledge absorption capability from the perspective of absorptive capacity theory, which itself has been widely used in the study of enterprise innovation performance [101]. However, most studies have mainly focused on knowledge absorption capacity at the organizational level, but rarely from the individual level. Thus, we choose knowledge absorption coefficient as an important parameter involved in the evolutionary game model.

$C_{i}$ : Knowledge-sharing cost coefficient, $C_{i}$, reflects the ability of the knowledge provider to control costs during knowledge-sharing. The higher the value of $C_{i}$, the weaker of the cost control capability. Cost control positively takes a series of prevention and adjustment measures to ensure the realization of cost management goals. This is carried out by an enterprise or project team, with the scope of its functions and powers, and according to preestablished cost objectives. It fully makes use of the principles of system engineering to calculate and supervise all kinds of costs incurred in the production and operation process. Cost control is also a process of discovering weakness, tapping internal potential, and finding all possible ways to reduce cost. The construction project is the basic part of construction industry in which cost control is particularly important. Scientific organization and implementation of cost control can promote enterprises to improve operation and management, help change the operation mechanism, and enhance the competitiveness of the project team members. The importance of cost control capability cannot be overstated, because only when the construction cost of the project is reduced to a reasonable range, can the enterprise and project team improve benefits and maintain virtuous development. Therefore, the knowledge-sharing cost efficient as an important parameter is introduced into the evolutionary game model.

4.2. Hypothesis. H1: The game is regarded as an unobservable system that comprises two game players: Group 1 and Group 2.

First of all, although the IPD team is comprised of multidisciplinary stakeholders, to simplify the study without loss of generality, two groups, Group 1 and Group 2, are selected randomly as the game players. Each group can play the role of the knowledge receiver or provider.

Next, all players obtain the information about themselves and the others before making a decision. In other words, owing to the incomplete information characteristic, the two groups select their strategies simultaneously, and neither can observe the other player's choice and whether the payoff obtained from the other part is attractive or not, while making decisions. Therefore, this game is an unobserved system that is in alignment with the bounded rationality assumption of the evolutionary.

H2: The pure strategy set for each group is set to be "share" and "not share" strategies, with the proportion of $x / y$ and $1-x / 1-y$ for Group 1 and Group 2, respectively.

H3: The Revenue obtained from the "not share" strategy is assumed to be $R_{i}$, of which $\mathrm{i}=(1,2)$.

H4: The value-added benefit including direct and synergetic benefits will be obtained by two groups when both groups adopt the "share" strategy.

Direct benefit refers to the benefit acquired by the knowledge receiver absorbing knowledge from knowledge provider. For the knowledge receiver such as Group 1, the direct benefit is subject to the degree of knowledge-sharing $\eta_{2}$, the heterogeneous knowledge proportion $u_{2}$, knowledge absorption capability $\alpha_{1}$, and the knowledge provider's knowledge stock $K_{2}$, namely, $\alpha_{1} \mu_{2} K_{2} \eta_{2}$. Similarly, the direct benefit for Group 2 is $\alpha_{2} \mu_{1} K_{1} \eta_{1}$.

For one participant, the amount of knowledge fusion is the sum of knowledge shared by this participant and knowledge by absorbing the other participant's knowledge $K_{i} \eta_{i}+\alpha_{i} \mu_{i} K_{i} \eta_{i}$. Specifically, the amount of knowledge fusion for Group 1 and Group 2 is $K_{1} \eta_{1}+\alpha_{1} \mu_{2} K_{2} \eta_{2}$ and $K_{2} \eta_{2}+\alpha_{2} \mu_{1} K_{1} \eta_{1}$, respectively. Synergetic benefit is subject to the synergetic capability coefficient $\beta_{i}$ and the amount of knowledge fusion $K_{i} \eta_{i}+\alpha_{i} \mu_{i} K_{i} \eta_{i}$. Therefore, for Group 1 and Group 2, the synergetic benefit is $\beta_{1}\left(K_{1} \eta_{1}+\alpha_{1} \mu_{2} K_{2} \eta_{2}\right)$ and $\beta_{2}\left(K_{2} \eta_{2}+\alpha_{2} \mu_{1} K_{1} \eta_{1}\right)$, respectively.

H5: The knowledge-sharing cost is subject to the knowledge-sharing cost coefficient $C_{i}$ and the amount of knowledge that can be shared by the participant $K_{i} \eta_{i}$.

According to the hypothesis mentioned above, the payoff matrix (Table 1) can be obtained. In the evolutionary game theory, payoff matrix, also known as "winning matrix", is used to describe the strategies and payments of two or more game players. It comprises alternative action plans, natural states, profit, and loss (or utility) values. As described in Table 1 , in the scenario $\left(A_{1}, B_{1}\right)$, both participants obtain 
TABle 1: Payoff matrix.

\begin{tabular}{lcc}
\hline Group 1 & Group 2 & $B_{2}(1-y)$ \\
& $B_{1}(y)$ & $R_{1}-C_{1} K_{1} \eta_{1}$ \\
$A_{1}(x)$ & $R_{1}+\alpha_{1} \mu_{2} K_{2} \eta_{2}+\beta_{1}\left(K_{1} \eta_{1}+\alpha_{1} \mu_{2} K_{2} \eta_{2}\right)-C_{1} K_{1} \eta_{1}$ & $R_{2}+\alpha_{2} \mu_{1} K_{1} \eta_{1}$ \\
$A_{2}(1-x)$ & $R_{2}+\alpha_{2} \mu_{1} K_{1} \eta_{1}+\beta_{2}\left(K_{2} \eta_{2}+\alpha_{2} \mu_{1} K_{1} \eta_{1}\right)-C_{2} K_{2} \eta_{2}$ & $R_{1}, R_{2}$ \\
\hline
\end{tabular}

direct and synergetic benefits. Meanwhile, it costs $C_{1} K_{1} \eta_{1}$ and $C_{2} K_{2} \eta_{2}$, respectively, to perform strategy $\left(A_{1}, B_{1}\right)$. Therefore, the total payoff acquired is $R_{1}+\alpha_{1} \mu_{2} K_{2} \eta_{2}+$ $\beta_{1}\left(K_{1} \eta_{1}+\alpha_{1} \mu_{2} K_{2} \eta_{2}\right)-C_{1} K_{1} \eta_{1}$ and $R_{2}+\alpha_{2} \mu_{1} K_{1} \eta_{1}+\beta_{2}$ $\left(K_{2} \eta_{2}+\alpha_{2} \mu_{1} K_{1} \eta_{1}\right)-C_{2} K_{2} \eta_{2}$, respectively. If Group 1 chooses to share knowledge and Group 2 does not to share knowledge, namely strategy $\left(A_{1}, B_{2}\right)$, the former will bear cost with no benefit, whereas the latter will obtain direct benefit with no cost. Therefore, the total payoff for both participants is $R_{1}-C_{1} K_{1} \eta_{1}$ and $R_{2}+\alpha_{2} \mu_{1} K_{1} \eta_{1}$. Similarly, the payoff is $R_{1}+\alpha_{1} \mu_{2} K_{2} \eta_{2}$ and $R_{2}-C_{2} K_{2} \eta_{2}$ for Group 1 and Group 2 in scenario $\left(A_{2}, B_{1}\right)$, respectively. If two groups all choose not to share knowledge, they will not obtain any direct and synergetic benefits. Hence, the payoff for Group 1 and Group 2 is $R_{1}, R_{2}$ respectively.

4.3. Evolutionary Game Model. The expected benefit of Group 1 that agrees to choose strategy $A_{1}$ is $E_{1}^{a}$ :

$$
\begin{aligned}
E_{1}^{a}= & y\left(R_{1}+\alpha_{1} \mu_{2} K_{2} \eta_{2}+\beta_{1}\left(K_{1} \eta_{1}+\alpha_{1} \mu_{2} K_{2} \eta_{2}\right)-C_{1} K_{1} \eta_{1}\right) \\
& +(1-y)\left(R_{1}-C_{1} K_{1} \eta_{1}\right) .
\end{aligned}
$$

The expected benefit of Group 1 that does not agree to choose strategy $A_{2}$ is $E_{1}^{n}$ :

$$
E_{1}^{n}=y\left(R_{1}+\alpha_{1} \mu_{2} K_{2} \eta_{2}\right)+(1-y) R_{1} .
$$

The expected average benefit of Group 1 under the mixed strategy is $\overline{E_{1}}$ :

$$
\begin{aligned}
\overline{E_{1}}= & x E_{1}^{a}+(1-x) E_{1}^{n}=y \alpha_{1} \mu_{2} K_{2} \eta_{2}+x \beta_{1} \alpha_{1} \mu_{2} K_{2} \eta_{2} \\
& +x y \beta_{1} K_{1} \eta_{1}-x C_{1} K_{1} \eta_{1} .
\end{aligned}
$$

According to the evolutionary game theory, if the benefit of a strategy adopted by one game player is higher than the average population, the strategy diffuses within the entire population. Then, the frequency of the game players choosing the strategy will improve within the population. The dynamic differential equation, which is referred to as the replication dynamic equation, can be utilized to depict the frequency of the strategy adopted within the population. On the basis of equations (1) and (3), the replication dynamic equation of Group 1 is

$$
\begin{aligned}
f_{A}= & \frac{d x}{d t}=x\left(E_{1}^{a}-\overline{E_{1}}\right)=x(1-x) \\
& \cdot\left[\beta_{1} y\left(K_{1} \eta_{1}+\alpha_{1} \mu_{2} K_{2} \eta_{2}\right)-C_{1} K_{1} \eta_{1}\right] .
\end{aligned}
$$

Similarly, the expected benefit of Group 2 that agrees to choose strategy $B_{1}$ is $E_{2}^{a}$ :

$$
\begin{aligned}
E_{2}^{a}= & x\left(R_{2}+\alpha_{2} \mu_{1} K_{1} \eta_{1}+\beta_{2}\left(K_{2} \eta_{2}+\alpha_{2} \mu_{1} K_{1} \eta_{1}\right)-C_{2} K_{2} \eta_{2}\right) \\
& +(1-x)\left(R_{2}-C_{2} K_{2} \eta_{2}\right) .
\end{aligned}
$$

The expected benefit of Group 2 that does not agree to choose strategy $B_{2}$ is $E_{2}^{n}$ :

$$
E_{2}^{n}=x\left(R_{2}+\alpha_{2} \mu_{1} K_{1} \eta_{1}\right)+(1-x) R_{2} .
$$

The expected average benefit of Group 2 is

$$
\begin{aligned}
\overline{E_{2}}= & y E_{2}^{a}+(1-y) E_{2}^{n}=x \alpha_{2} \mu_{1} K_{1} \eta_{1}+x y \beta_{2} \alpha_{2} \mu_{1} K_{1} \eta_{1} \\
& +y x \beta_{2} K_{2} \eta_{2}-y C_{2} K_{2} \eta_{2} .
\end{aligned}
$$

According to equations (5) and (7), the replication dynamic equation that is constructed is

$$
\begin{aligned}
f_{B}= & \frac{d y}{d t}=y\left(E_{2}^{a}-\overline{E_{2}}\right)=y(1-y) \\
& \cdot\left[\beta_{2} x\left(K_{2} \eta_{2}+\alpha_{2} \mu_{1} K_{1} \eta_{1}\right)-C_{2} K_{2} \eta_{2}\right] .
\end{aligned}
$$

From equations (4) and (8), a two-dimensional nonlinear dynamic system can be acquired:

$$
\left\{\begin{array}{l}
\frac{d x}{d t}=x(1-x)\left[\beta_{1} y\left(K_{1} \eta_{1}+\alpha_{1} \mu_{2} K_{2} \eta_{2}\right)-C_{1} K_{1} \eta_{1}\right]=0 \\
\frac{d y}{d t}=y(1-y)\left[\beta_{2} x\left(K_{2} \eta_{2}+\alpha_{2} \mu_{1} K_{1} \eta_{1}\right)-C_{2} K_{2} \eta_{2}\right]=0
\end{array}\right.
$$

Based on the solution of equation (9), we can obtain five local equilibrium points (LEP) from the nonlinear dynamic system: $\mathrm{A}(0,0), \mathrm{B}(0,1), \mathrm{C}(1,0), \mathrm{D}(1,1), \mathrm{E}\left(x^{*}, y^{*}\right)$, wherein

$$
\left\{\begin{array}{l}
x^{*}=\frac{C_{2} K_{2} \eta_{2}}{\beta_{2}\left(K_{2} \eta_{2}+\alpha_{2} \mu_{1} K_{1} \eta_{1}\right)}, \\
y^{*}=\frac{C_{1} K_{1} \eta_{1}}{\beta_{1}\left(K_{1} \eta_{1}+\alpha_{1} \mu_{2} K_{2} \eta_{2}\right)} .
\end{array}\right.
$$

Full advantage of the Jacobian matrix $(J)$ is taken to qualitatively analyze the five LEP. The Jacobian matrix that can be obtained from the game is

$$
J=\left[\begin{array}{ll}
\frac{\partial f_{A}}{\partial x} & \frac{\partial f_{A}}{\partial y} \\
\frac{\partial f_{B}}{\partial x} & \frac{\partial f_{B}}{\partial y}
\end{array}\right]
$$

Therefore, 


$$
\begin{aligned}
& \frac{\partial f_{A}}{\partial x}=(1-2 x)\left(y \beta_{1} \alpha_{1} \mu_{2} K_{2} \eta_{2}+y \beta_{1} \alpha_{1} K_{1} \eta_{1}-C_{1} K_{1} \eta_{1}\right), \\
& \frac{\partial f_{A}}{\partial y}=x(1-x) \beta_{1}\left(\alpha_{1} \mu_{2} K_{2} \eta_{2}+K_{1} \eta_{1}\right), \\
& \frac{\partial f_{B}}{\partial x}=y(1-y) \beta_{1}\left(\alpha_{1} \mu_{2} K_{2} \eta_{2}+K_{1} \eta_{1}\right), \\
& \frac{\partial f_{B}}{\partial y}=(1-2 y)\left(x \beta_{2} \alpha_{2} \mu_{1} K_{1} \eta_{1}+x \beta_{2} \alpha_{2} K_{2} \eta_{2}-C_{2} K_{2} \eta_{2}\right) .
\end{aligned}
$$

Based on Friedman's theory, we can conclude that $A, B$, $C$, and $D$ are local pure strategy equilibrium points. Additionally, $\mathrm{E}$ is a local equilibrium point that has a mixed strategy. With respect to the stability of the five points, it can be acquired by analyzing the determinant $(\operatorname{det}(J))$ and trace $(\operatorname{tr}(J))$ of the Jacobian matrix. For any point, $\operatorname{det}(J)=\left(\partial f_{A} / \partial x\right) *\left(\partial f_{B} / \partial y\right)-\left(\partial f_{A} / \partial y\right) *\left(\partial f_{B} / \partial x\right)$ and $\operatorname{tr}(J)=\left(\partial f_{A} / \partial x\right)+\left(\partial f_{B} / \partial y\right)$. Specifically, the values of $\operatorname{det}(J)$ and $\operatorname{tr}(J)$ of the Jacobian in the five points mentioned above are presented in Table 2 .

For a certain point that satisfies the evolutionary game stable state (ESS), it is subject to $\operatorname{det}(J)>0$ and $\operatorname{tr}(J)<0$, and it possesses the asymptotic stability. Thereby, the corresponding strategy portfolio is regarded as a stable equilibrium solution. If $\operatorname{det}(J) \geq 0$ and $\operatorname{tr}(J)>0$, the point is defined as unstable. If $\operatorname{det}(J)>0$ and $\operatorname{tr}(J)=0$, the point is defined as neutral. Additionally, if $\operatorname{det}(J)<0$, the point is defined as a saddle point.

4.4. Model Analysis. In terms of the range of values for $x^{*}$ and $y^{*}$, four scenarios are derived from the evolutionary game. Each equilibrium point and its stability decision process under the corresponding scenario are presented in Table 3.

\section{Simulation of the Model}

For the purpose of further understanding the theoretical results analyzed in Section 4, we develop a program to simulate the evolutionary process of interaction behaviors among integrated project team members. The simulation is conducted using MATLAB 2016a. The Runge-Kutta method, embedded in the simulation platform, is introduced to settle the differential equation group of the dynamic replicator system.

Function ode 45 which is built in MATLAB platform is used to obtain the simulation solutions. Parameter setting should be completed before implementing the simulation. The evolutionary time span is limited to the range of values $[0,10]$, and the initial point is assumed to be $P\left(x_{0}, y_{0}\right)$, wherein $0 \leq x_{0}, y_{0} \leq 1$. According to the model parameters mentioned in Section 4.1, the base values are set to $K_{1}=20000, \quad K_{2}=10000, \quad \eta_{1}=0.5, \quad \eta_{2}=0.5, \quad \beta_{1}=0.1$, $\beta_{2}=0.1, \alpha_{1}=0.2, \alpha_{2}=0.5, \mu_{1}=0.2$, and $\mu_{2}=0.5$.

5.1. Verification for Evolutionary Tendency. With the other model variables in line with the base values, the parameters
$C_{1}$ and $C_{2}$ are set to 0.05 under conditions $0<x^{*}<1$ and $0<y^{*}<1$. That is to say, the evolutionary tendency of knowledge-sharing is subject to the conditions $C_{2} K_{2} \eta_{2}<\beta_{2}\left(K_{2} \eta_{2}+\alpha_{2} \mu_{1} K_{1} \eta_{1}\right)$ and $C_{1} K_{1} \eta_{1}<\beta_{1}\left(K_{1} \eta_{1}+\right.$ $\left.\alpha_{1} \mu_{2} K_{2} \eta_{2}\right)$. In this scenario, 100 array points are selected randomly as the initial evolutionary points that represent the proportion of the integrated project team members who choose the "share" strategy in Group 1 and Group 2, respectively. The evolutionary outcome is described in Figure 2(a). We can conclude that the general evolutionary path is attracted to the two stable points, namely, point $(0,0)$ and point $(1,1)$, which is in accordance with 1(a).

With the other model variables consistent with the base values, the parameters $C_{1}$ and $C_{2}$ are set to 0.05 and 0.5 , respectively, under the condition $x^{*}>1$ and $0<y^{*}<1$. That is to say, the evolutionary tendency of knowledge-sharing is subject to the condition that $C_{2} K_{2} \eta_{2}>\beta_{2}\left(K_{2} \eta_{2}+\alpha_{2} \mu_{1} K_{1} \eta_{1}\right)$ and $C_{1} K_{1} \eta_{1}<\beta_{1}\left(K_{1} \eta_{1}+\alpha_{1} \mu_{2} K_{2} \eta_{2}\right)$. In this scenario, 100 array points are selected randomly as the initial evolutionary points that represent the proportion of the integrated project team members who choose the "share" strategy in Group 1 and Group 2, respectively. The evolutionary result is depicted in Figure 2(b). We can see that the general evolutionary path is attracted to stable points $(0,0)$, which is consistent with $1(\mathrm{~b})$.

With the other model variables consistent with the base values, the parameters $C_{1}$ and $C_{2}$ are set to 0.5 and 0.05 , respectively, under the conditions $0<x^{*}<1$ and $y^{*}>1$. That is to say, the evolutionary tendency of knowledge-sharing is subject to the conditions $C_{2} K_{2} \eta_{2}<\beta_{2}\left(K_{2} \eta_{2}+\alpha_{2} \mu_{1} K_{1} \eta_{1}\right)$ and $C_{1} K_{1} \eta_{1}>\beta_{1}\left(K_{1} \eta_{1}+\alpha_{1} \mu_{2} K_{2} \eta_{2}\right)$. Then, 100 array points are selected randomly as the initial evolutionary points that represent the proportion of integrated project team members who choose the strategy "share" in Group 1 and Group 2 , respectively. The evolutionary result is shown in Figure 2(c). We can see that the general evolutionary path is attracted to the stable point $(0,0)$, which is in line with 1 (c).

With the other model parameters remaining the same as the base values, the parameters $C_{1}$ and $C_{2}$ are set to 0.5 under the condition $x^{*}>1, y^{*}>1$. That is to say, the evolutionary tendency of knowledge-sharing is subject to the conditions $C_{2} K_{2} \eta_{2}>\beta_{2}\left(K_{2} \eta_{2}+\alpha_{2} \mu_{1} K_{1} \eta_{1}\right)$ and $C_{1} K_{1} \eta_{1}>\beta_{1}\left(K_{1} \eta_{1}+\right.$ $\left.\alpha_{1} \mu_{2} K_{2} \eta_{2}\right)$. Then, 100 array points are selected randomly as the initial evolutionary points that represent the proportion of integrated project team members who choose the strategy "share" in Group 1 and Group 2, respectively. The evolutionary result is illustrated in Figure 2(d). We can see that the general evolutionary path is convergent to the stable point $(0,0)$, which is in line with $1(d)$.

In Figures 2(b)-2(d), we can see that the integrated project team members in both Group 1 and Group 2 will eventually choose strategy $\left(A_{2}, B_{2}\right)$ under scenario 2 , scenario 3 , and scenario 4 . Hence, the evolution trend is certain and clear. In Figure 2(a), we can see that the two conditions exist under condition $0<x^{*}<1$ and $0<y^{*}<1$. When the initial points are located in the upper right area, the behaviors of both groups either converge to point $(0,0)$ indicating that both groups will choose the "not share" strategy, or converge to the point $(1,1)$ indicating that both 
TABle 2: Determinant and trace of Jacobian.

\begin{tabular}{|c|c|}
\hline LEP & The determinant and trace of $J$ \\
\hline \multirow{2}{*}{$A(0,0)$} & $\operatorname{det}(J)=C_{1} K_{1} \eta_{1} C_{2} K_{2} \eta_{2}$ \\
\hline & $\operatorname{tr}(J)=-\left(C_{1} K_{1} \eta_{1}+C_{2} K_{2} \eta_{2}\right)$ \\
\hline \multirow{2}{*}{$B(0,1)$} & $\operatorname{det}(J)=C_{2} K_{2} \eta_{2}\left(\beta_{1} K_{1} \eta_{1} C_{2} K_{2} \eta_{2}+\beta_{1} \alpha_{1} \mu_{2} K_{2} \eta_{2} C_{2} K_{2} \eta_{2}-C_{1} K_{1} \eta_{1}\right)$ \\
\hline & $\operatorname{tr}(J)=\left(\beta_{1} K_{1} \eta_{1}+\beta_{1} \alpha_{1} \mu_{2} K_{2} \eta_{2}-C_{1} K_{1} \eta_{1}\right)+C_{2} K_{2} \eta_{2}$ \\
\hline \multirow{2}{*}{$C(1,0)$} & $\operatorname{det}(J)=C_{1} K_{1} \eta_{1}\left(\beta_{2} K_{2} \eta_{2}+\beta_{2} \alpha_{2} \mu_{1} K_{1} \eta_{1}-C_{2} K_{2} \eta_{2}\right)$ \\
\hline & $\operatorname{tr}(J)=C_{1} K_{1} \eta_{1}+\left(\beta_{2} K_{2} \eta_{2}+\beta_{2} \alpha_{2} \mu_{1} K_{1} \eta_{1}-C_{2} K_{2} \eta_{2}\right)$ \\
\hline \multirow{2}{*}{$D(1,1)$} & $\operatorname{det}(J)=\left[C_{1} K_{1} \eta_{1}-\beta_{1}\left(K_{1} \eta_{1}+\alpha_{1} \mu_{2} K_{2} \eta_{2}\right)\right]\left[C_{2} K_{2} \eta_{2}-\beta_{2}\left(K_{2} \eta_{2}+\alpha_{2} \mu_{1} K_{1} \eta_{1}\right)\right]$ \\
\hline & $\operatorname{tr}(J)=\left[C_{1} K_{1} \eta_{1}-\beta_{1}\left(K_{1} \eta_{1}+\alpha_{1} \mu_{2} K_{2} \eta_{2}\right)\right]+\left[C_{2} K_{2} \eta_{2}-\beta_{2}\left(K_{2} \eta_{2}+\alpha_{2} \mu_{1} K_{1} \eta_{1}\right)\right]$ \\
\hline \multirow[t]{2}{*}{$E\left(x^{*}, y^{*}\right)$} & $\begin{aligned} \operatorname{det}(J)= & \left(-\left(\beta_{1} K_{1} \eta_{1}+\beta_{1} \alpha_{1} \mu_{2} K_{2} \eta_{2}-C_{1} K_{1} \eta_{1}\right)\left(\beta_{2} K_{2} \eta_{2}+\beta_{2} \alpha_{2} \mu_{1} K_{1} \eta_{1}-C_{2} K_{2} \eta_{2}\right)\right. \\
& \left.C_{1} K_{1} \eta_{1} C_{2} K_{2} \eta_{2}\right) /\left(\beta_{1}\left(K_{1} \eta_{1}+\alpha_{1} \mu_{2} K_{2} \eta_{2}\right) \beta_{2}\left(K_{2} \eta_{2}+\alpha_{2} \mu_{1} K_{1} \eta_{1}\right)\right)\end{aligned}$ \\
\hline & $\operatorname{tr}(J)=0$ \\
\hline
\end{tabular}

TABLE 3: The equilibrium stability of the nonlinear dynamic system for four scenarios.

\begin{tabular}{|c|c|c|c|c|c|c|}
\hline Scenarios & Range of values & Points & $\operatorname{det}(J)$ & $\operatorname{tr}(J)$ & Equilibrium results & Phase diagrams \\
\hline \multirow{5}{*}{ Scenario 1} & \multirow{5}{*}{$0<x^{*}<1,0<y^{*}<1$} & $(0,0)$ & + & - & ESS & \multirow{5}{*}{ Figure 1(a) } \\
\hline & & $(0,1)$ & + & + & Unstable & \\
\hline & & $(1,0)$ & + & + & Unstable & \\
\hline & & $(1,1)$ & + & - & ESS & \\
\hline & & $\left(x^{*}, y^{*}\right)$ & + & 0 & Saddle & \\
\hline \multirow{5}{*}{ Scenario 2} & \multirow{5}{*}{$x^{*}>1,0<y^{*}<1$} & $(0,0)$ & + & - & ESS & \multirow{5}{*}{ Figure 1(b) } \\
\hline & & $(0,1)$ & - & Uncertain & Saddle & \\
\hline & & $(1,0)$ & + & + & Unstable & \\
\hline & & $(1,1)$ & - & Uncertain & Saddle & \\
\hline & & $\left(x^{*}, y^{*}\right)$ & + & 0 & Neutral & \\
\hline \multirow{5}{*}{ Scenario 3} & \multirow{5}{*}{$0<x^{*}<1, y^{*}>1$} & $(0,0)$ & + & - & ESS & \multirow{5}{*}{ Figure 1(c) } \\
\hline & & $(0,1)$ & + & + & Unstable & \\
\hline & & $(1,0)$ & - & Uncertain & Saddle & \\
\hline & & $(1,1)$ & - & Uncertain & Saddle & \\
\hline & & $\left(x^{*}, y^{*}\right)$ & + & 0 & Neutral & \\
\hline \multirow{5}{*}{ Scenario 4} & \multirow{5}{*}{$x^{*}>1, y^{*}>1$} & $(0,0)$ & + & - & ESS & \multirow{5}{*}{ Figure 1(d) } \\
\hline & & $(0,1)$ & - & Uncertain & Saddle & \\
\hline & & $(1,0)$ & - & Uncertain & Saddle & \\
\hline & & $(1,1)$ & + & + & Unstable & \\
\hline & & $\left(x^{*}, y^{*}\right)$ & - & 0 & Saddle & \\
\hline
\end{tabular}

groups will choose the "share" strategy when the initial points are located in the lower left. Hence, the evolutionary outcome is uncertain in scenario 2, and we will further discuss the impact of the model parameters on the evolutionary tendency of interaction behaviors among integrated project team members in the following section.

5.2. Influence of $x$ and $y$. The proportion of the integrated project team members with different strategies in Group 1 and Group 2 is studied firstly. To set the simulation parameters $x$ and $y$ reasonably and ensure the reliability and extensibility of this research findings, we conducted semistructured interviews, through Internet search and social network relations. Thus, 20 experts with rich experience in project team management are chosen. These experts are divided as follows: $15 \%$ with three to five years of work experience, $35 \%$ with five to ten years of work experience and $50 \%$ with more than ten years of work experiences. We sorted out and adopted the suggestions proposed and accepted by the most experts.

Most experts argued that team members within a learning project team would show a strong tendency to cooperate. Within this, the proportion of the integrated project team members who would prefer to share knowledge plays an important role in cooperation. They also suggested that it was necessary to distinguish between different effort levels referring to the proportion of team members preferring to share knowledge at the early stage of organizing the project team. In terms of experts' suggestions, the numerical values from 0 to 1 with an addition of 0.1 were provided for the experts to identify the appropriate range of different effort level. According to the results of semistructured interviews, a value equal to or greater than 0.8 was considered the high effort level, and a value equal to or greater than 0.5 and less than 0.8 is regarded as the moderate effort level, and a value equal to or less than 0.5 is regarded as the low effort level. Hence, in this paper, three values of 0.2 , 


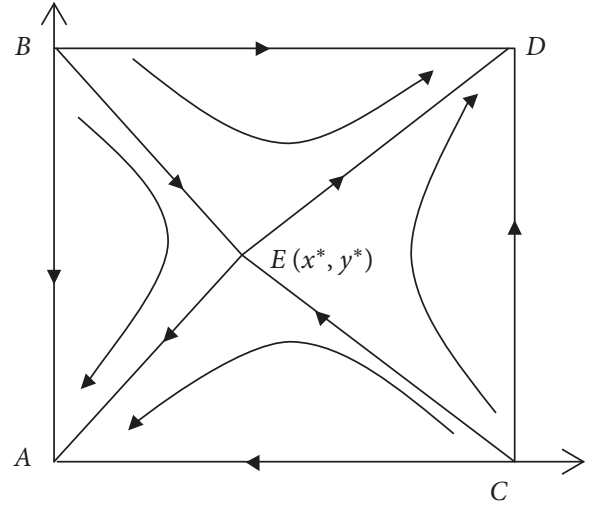

(a)

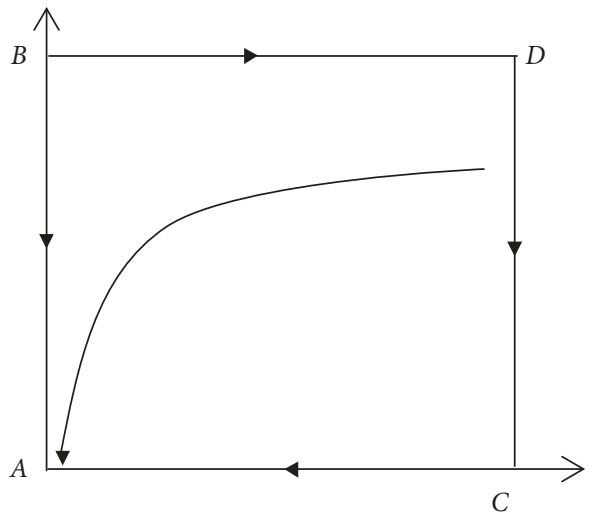

(c)

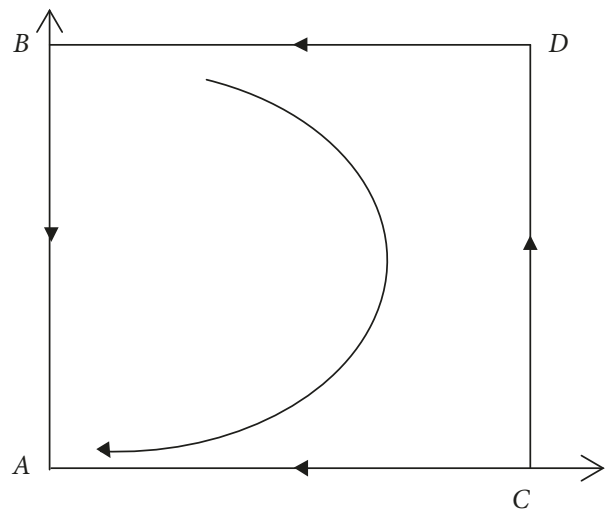

(b)

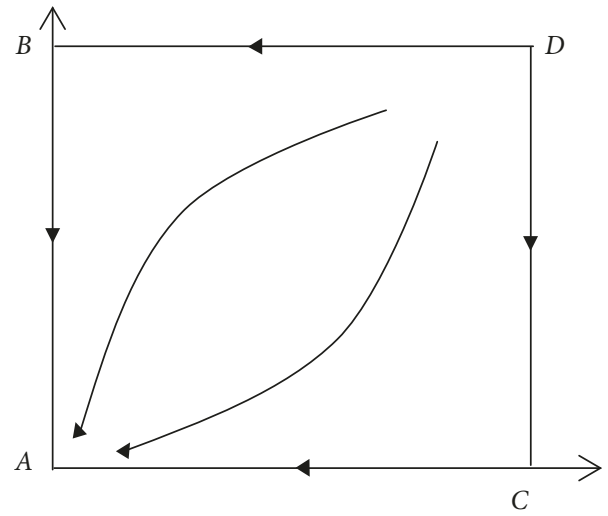

(d)

FIgURE 1: Phase portraits.

0.5 , and 0.8 are adopted to represent the low effort level, moderate effort level, and high effort level, respectively, to simulate the impact of $x$ and $y$ on the evolutionary trend.

With the other model parameters remaining the same with the base values, by setting $C_{1}=0.05$ and $C_{2}=0.05$, Figures 3(a)-3(c) elaborate the evolutionary trend of Group 1 under the condition that the fixed $y$ values are $0.2,0.5$, and 0.8 , which, respectively, represents the low effort, moderate effort, and high effort levels of Group 2. Comparing with Figures 3(a)-3(c), we can observe that the probability of choosing the "share" strategy in Group 1, even if at the low effort level, improves obviously with the increase in the proportion of team members choosing $B_{1}$ in Group 2. When $80 \%$ (i.e., high-level effort) of integrated project team members in Group 2 choose the "share" strategy, all the integrated project team members in Group 1 eventually choose to share their knowledge with the other team members in Group 2, as shown in Figure 3(c). When the proportion of the integrated team members in Group 2 is at moderate effort level (i.e., $y=0.5$ ), the integrated project team members with moderate and high effort levels (i.e., $x=0.5$ and $x=0.8$ ) in Group 1 are eventually attracted to strategy $A_{1}$, as shown in Figure 3(b). Furthermore, the smaller the initial value of $x$ is, the faster the evolution tendency of team members in Group 1 converges to 0 if the team members of Group 2 are at the low effort level (i.e., $y=0.2$ ), as shown in Figure 3(a). Similarly, Figures 4(a)-4(c) illustrate the evolutionary trend of Group 2 under the condition that the fixed $x$ values are $0.2,0.5$, and 0.8 . We observe the same results as in Figure 3.

Based on the analysis of the simulation results above, we can conclude the first interesting finding that if the integrated project team members in both groups are at moderate- or high-effort level, the interaction behaviors of both groups would evolve to the combined "share, share" strategy, which means that they will choose to share knowledge with each other. The second finding is obtained that as long as one of the two game players (Group 1 and Group 2) is at high effort level initially, it will drive the other game player to evolve to the "share" strategy, and both game players will share their own knowledge ultimately.

\subsection{Influence of Special Model Parameters}

\subsubsection{Influence of Heterogeneous Knowledge Proportion.} We first analyzed the influence of the heterogeneous knowledge proportion $\left(\mu_{i}\right)$ on two game players, which increases from 0.2 to 0.6 with a step length of 0.2 , by setting $C_{1}=0.05$ and $C_{2}=0.05$ and remaining the other parameters consistent with the base values. The initial point is assumed to be $(0.4,0.6)$. The simulation results are shown in Figures 5(a) and 5(b). The interesting finding is obtained that with the increase of the heterogeneous knowledge 


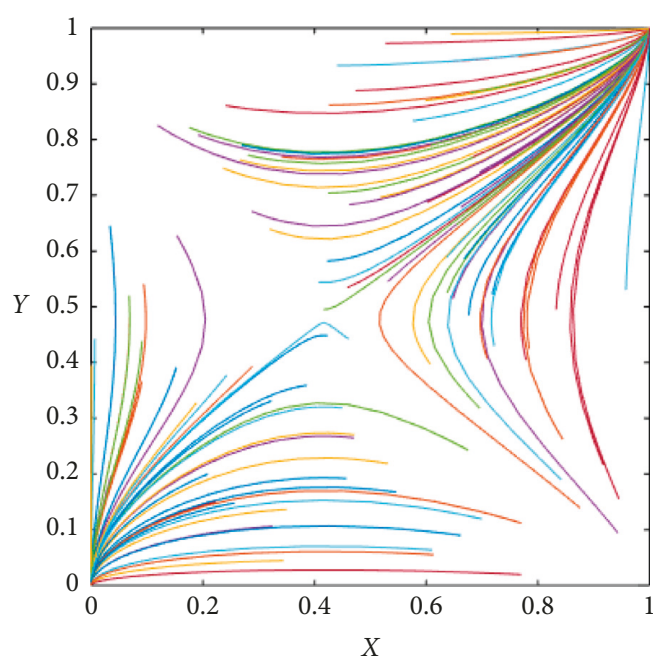

(a)

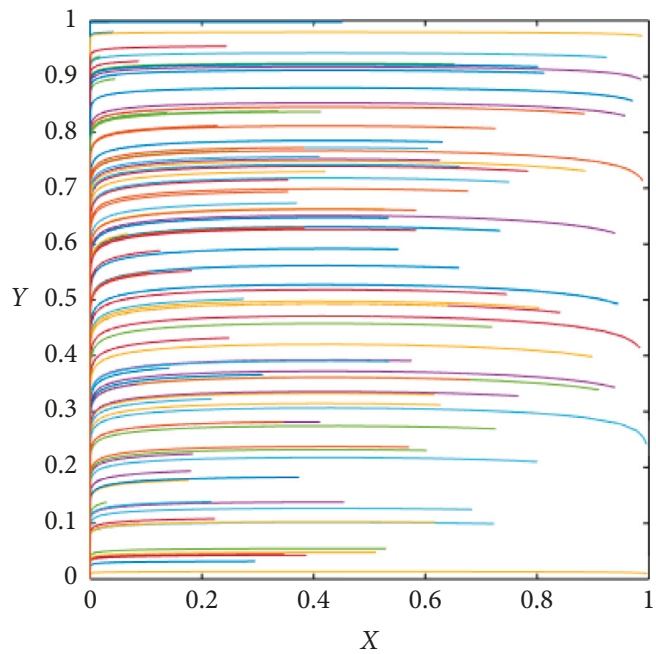

(c)

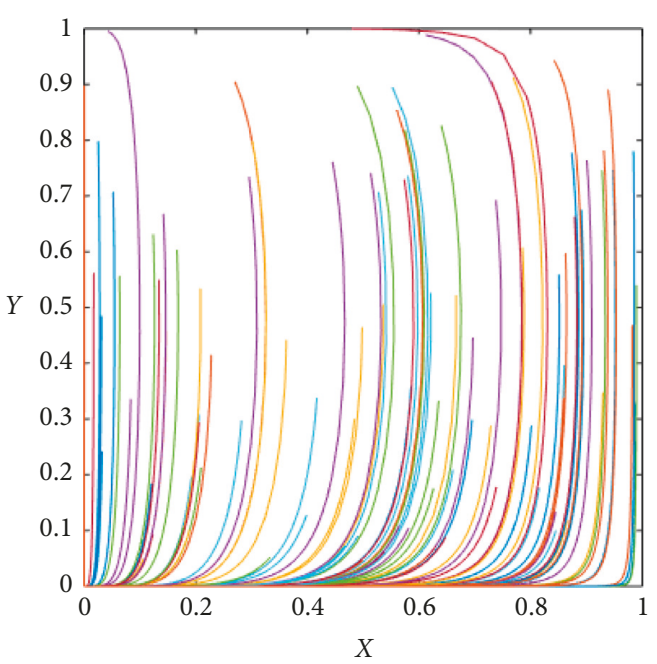

(b)

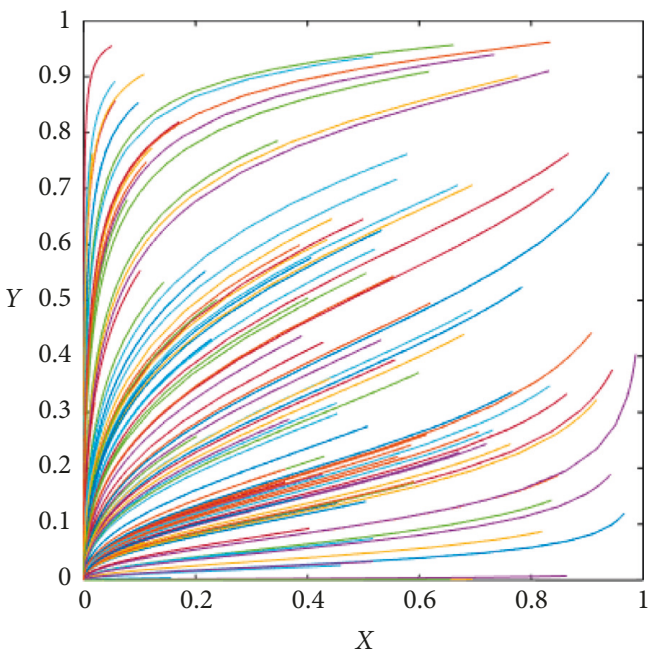

(d)

FIGURE 2: Evolutionary paths of scenarios 1 4: (a) scenario 1; (b) scenario 2; (c) scenario 3; (d) scenario 4.

proportion, both game players eventually evolve to the combined strategy "share, share", and the larger the values of $\mu_{i}$ are, the faster the values of $x$ and $y$ converge to 1 . That is, when heterogeneous knowledge proportion increases, the probability of adopting the combined strategy "share, share" increases for both game players.

5.3.2. Influence of Knowledge Absorption Coefficient. We then analyzed the impact of the knowledge absorption capability $\left(\alpha_{i}\right)$ on the choice of the combined strategy for both game players. By setting $C_{1}=0.05$ and $C_{2}=0.05$, the parameter $\alpha_{i}$ increases from 0.2 to 0.8 with a step length of 0.2 . We leave the remaining parameters unchanged, and the initial point is assumed to be $(0.4,0.6)$. The simulation outcomes are shown in Figures 5(c) and 5(d). We can conclude that with increase of $\alpha_{i}$, the proportion of choosing the strategy "share" by both game players eventually converges to 1 , and the larger the values of $\alpha_{i}$, the faster the rate of convergence. Thus, as $\alpha_{i}$ increases, the probability of adopting combined strategy "share, share" improves gradually.

5.3.3. Influence of Synergetic Effect Coefficient. Next, the influence of the heterogeneous knowledge proportion $\left(\beta_{i}\right)$ on the evolution results of the interaction behavior of the two game players was analyzed, by setting $C_{1}=0.05$ and $C_{2}=0.05$ and then leaving the remaining parameters unchanged. The parameter $\beta_{i}$ increases from 0.2 to 0.8 with a step length of 0.2 . The initial point is assumed to be $(0.4,0.6)$. The simulation results are shown in Figures 5(e) and 5(f). The interesting finding can be obtained that, with the increase of heterogeneous knowledge proportion, both game players eventually evolve to the combined strategy "share, share", and the larger the values of $\beta_{i}$, the faster the evolution results of the interaction behavior converge to 1 . That is, when the synergetic effect coefficient increases, the probability of adopting combined strategy "share, share" will be improved for both game players. 


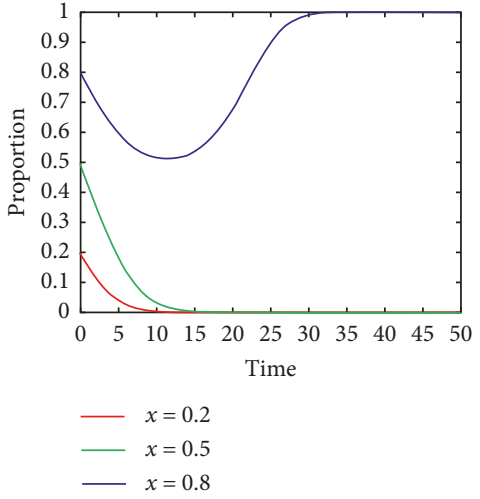

(a)

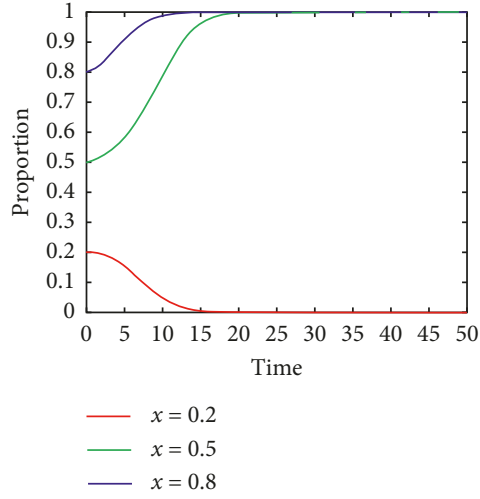

(b)

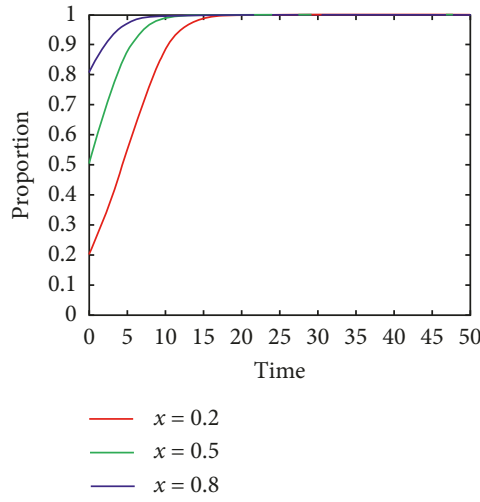

(c)

FIGURE 3: Evolutionary results of $x$ influenced by the different initial value of $y$ where (a) $y=0.2$, (b) $y=0.5$, and (c) $y=0.8$.

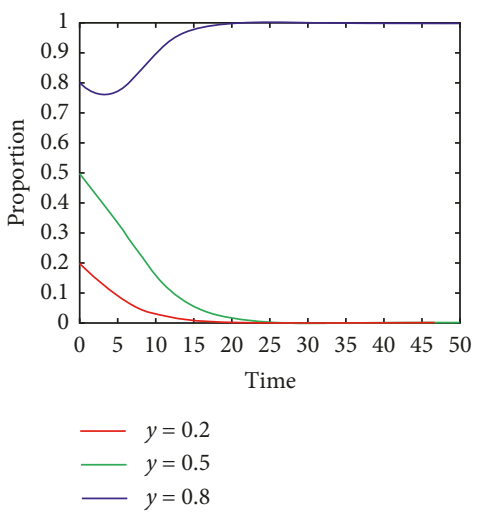

(a)

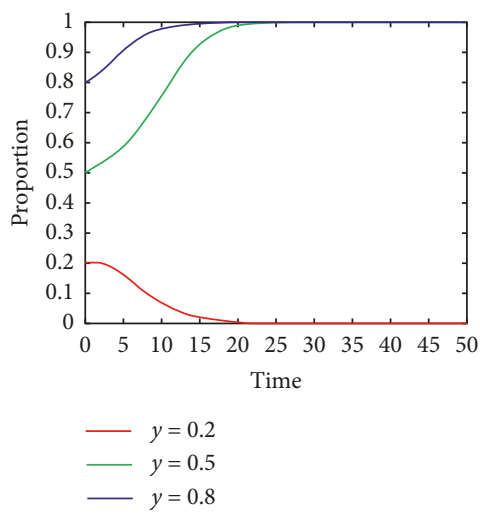

(b)

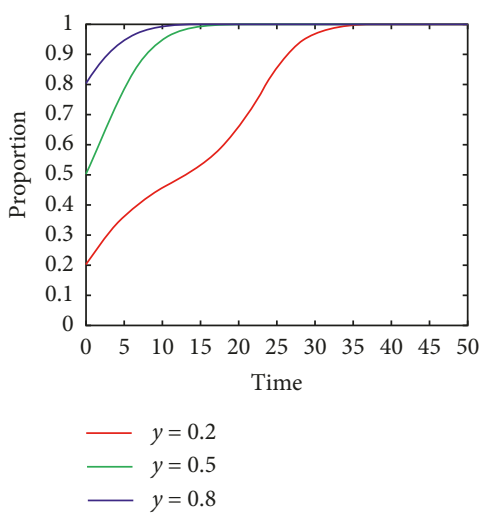

(c)

FIGURE 4: Evolutionary results of $y$ influenced by the different initial value of $x$ where (a) $x=0.2$, (b) $x=0.5$, and (c) $x=0.8$.

5.3.4. Influence of Knowledge-Sharing Cost Coefficient. Next, we evaluate the influence of the knowledge-sharing cost coefficient $\left(C_{i}\right)$ on the interaction behavior of both game players. First, the influence of parameter $C_{1}$ on both game players is analyzed, wherein $C_{1}$ increases from 0.03 to 0.06 with a step length of 0.01 , while $C_{2}=0.08$. The other model parameters have the same base values, and the initial point is assumed to be $(0.4,0.6)$. The simulation result is shown in Figure $5(\mathrm{~g})$. Second, we analyze the influences of parameter $C_{2}$ on both game players, wherein $C_{2}$ increases from 0.03 to 0.06 with a step length of 0.01 , and $C_{1}=0.08$. Remain the other model parameters the same with base values, and the initial point is assumed to be $(0.4,0.6)$. The simulation result is shown in Figure 5(h). The evolution results indicate that, when $C_{i}$ is small, the interaction behavior of both game players will eventually evolve to the combined strategy "share, share". However, as the parameter $C_{i}$ increases and reaches a certain level (e.g., $C_{i}=0.05$ or 0.06 ), the interaction behaviors of both game players will abandon the "share" strategy and eventually choose the combined strategy "not share, not share", which the project leader does not seek.

5.3.5. Influence of Knowledge Stock. By setting $C_{1}=0.05$ and $C_{2}=0.05$, the value of knowledge stock $\left(K_{i}\right)$ increases from
16,000 to 22,000 with a step length of 2,000, keeping the other model variables the same as the base values. The initial point is $(0.4,0.6)$. We then studied the impact of the numerical variation of the knowledge stock on the interaction behaviors of both game players. From the simulation results, as shown in Figures 5(i) and 5(j), we can observe that the larger the value of $K_{i}$ is, the faster the evolution results converge to 1 . That is, with the increase of $K_{i}$, the probability of choosing combined strategy "share, share" improves gradually.

5.3.6. Influence of Degree of Knowledge-Sharing. Finally, the influence of the degree of knowledge-sharing $\left(\eta_{i}\right)$ on the interaction behavior of both game players was analyzed. By setting $C_{1}=0.05$ and $C_{2}=0.05$, and keeping the other model variables the same as the base values, the values of $\eta_{1}$ increase from 0.2 to 0.8 with a step length of 0.2 . From the simulation results, as shown in Figures 5(k) and 5(l), we can see that, with the increase of degree of knowledge-sharing, the rate of evolution converging to 1 improves gradually. That is, improving the value of $\eta_{i}$ benefits the probability of adopting combined strategy "share, share" for both game players.

5.4. Result Discussion. We validated the novel evolutionary game model established in this study, by conducting detailed 


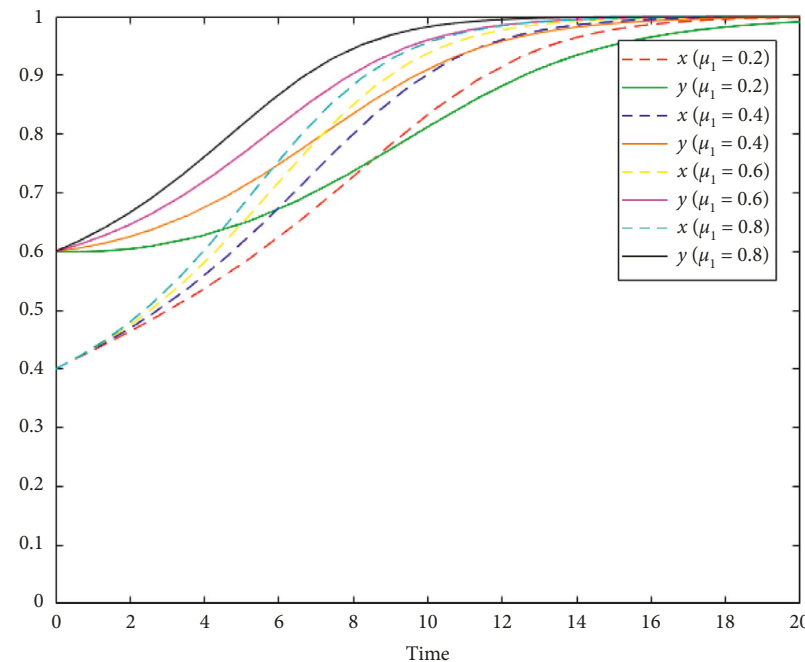

(a)

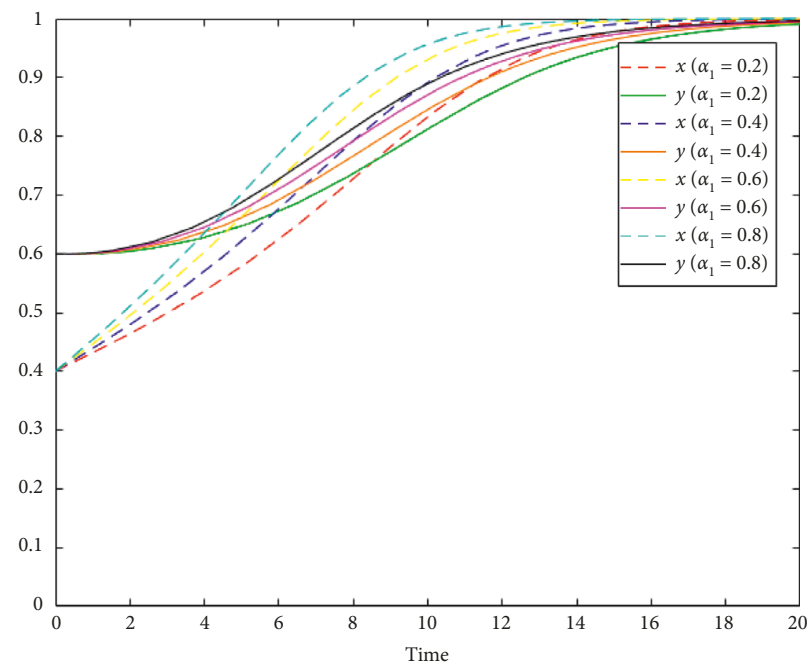

(c)

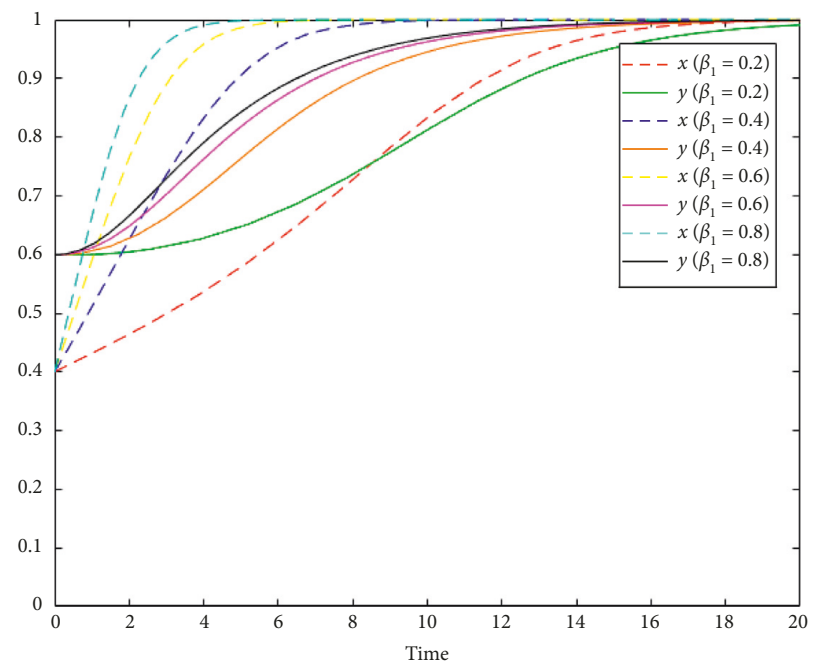

(e)

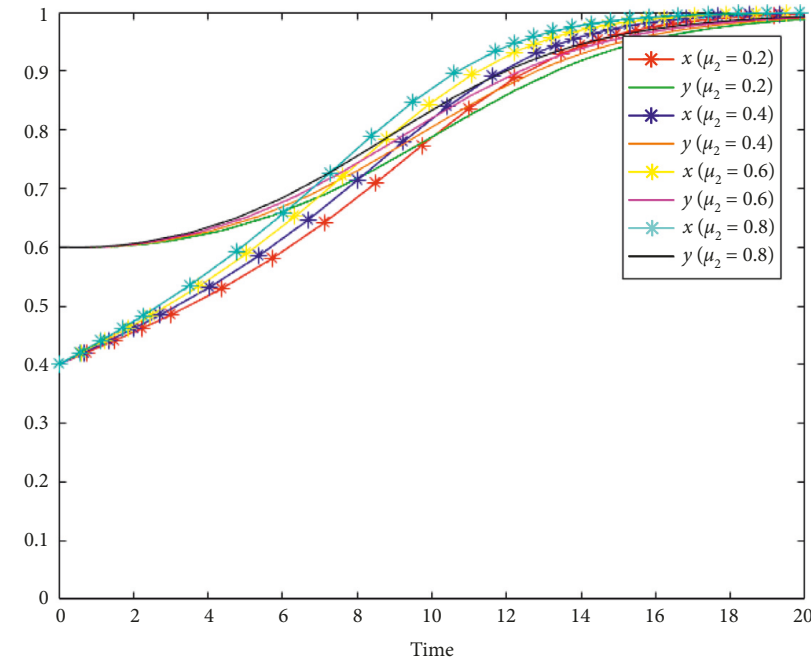

(b)

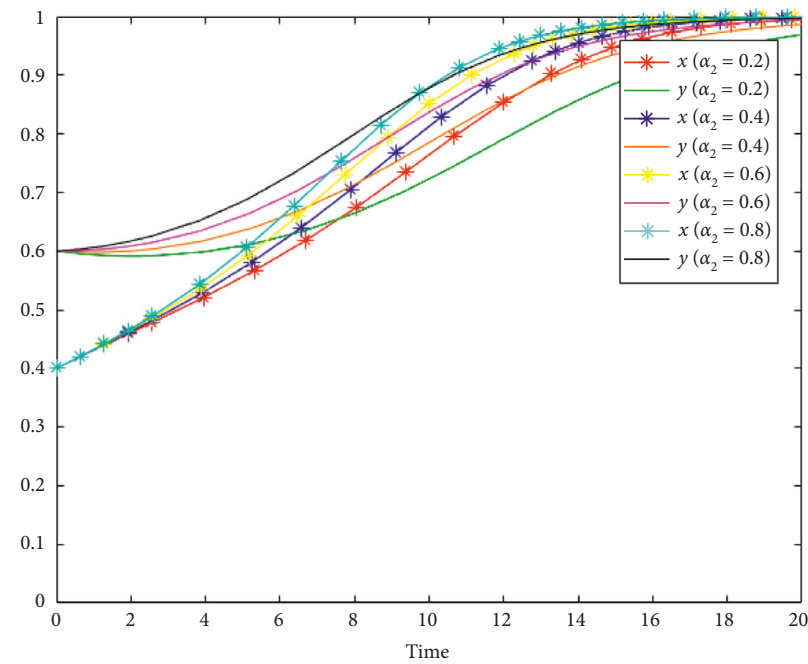

(d)

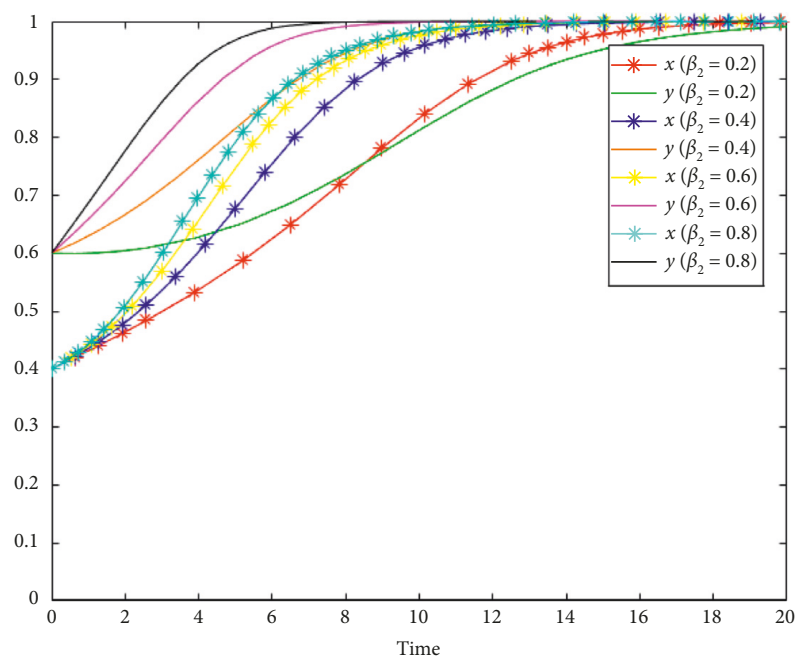

(f)

Figure 5: Continued. 


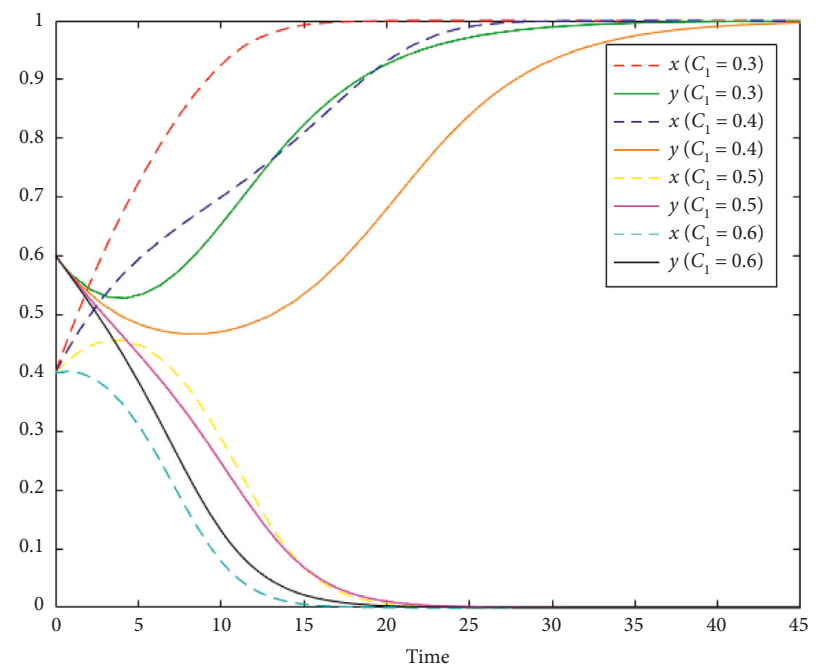

(g)

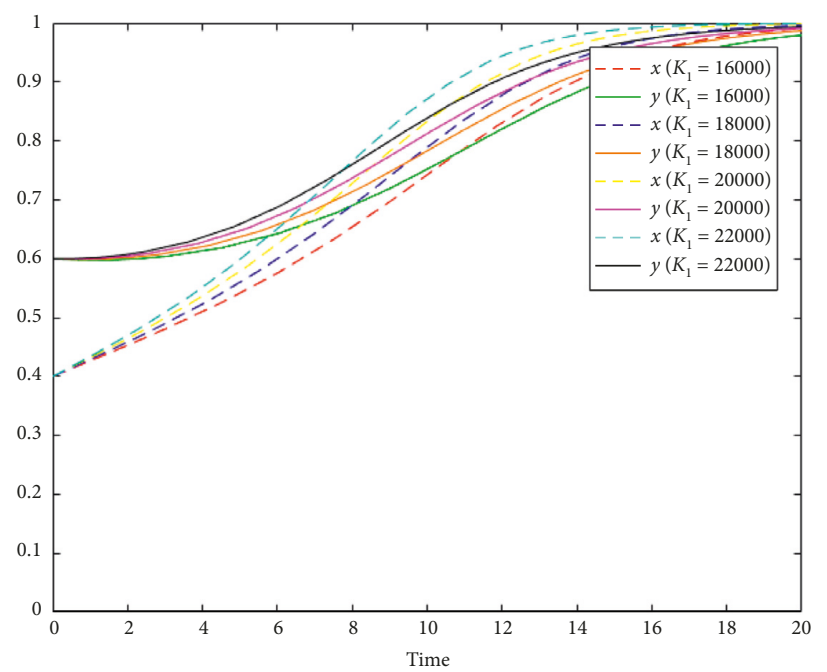

(i)

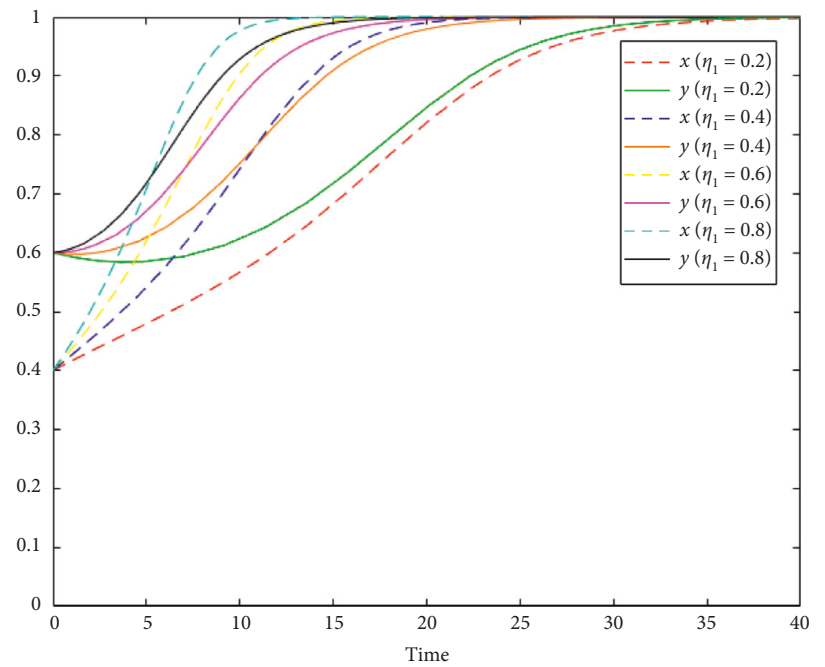

(k)

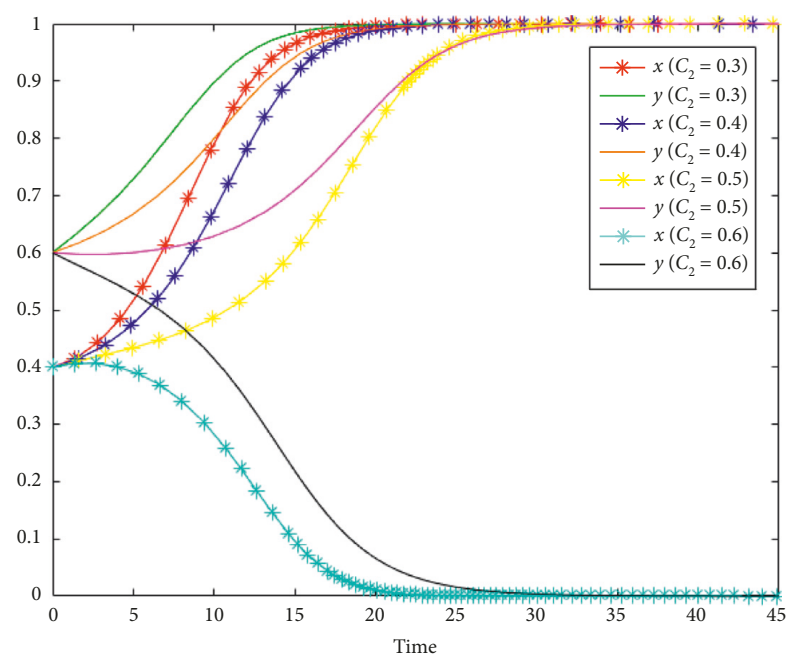

(h)

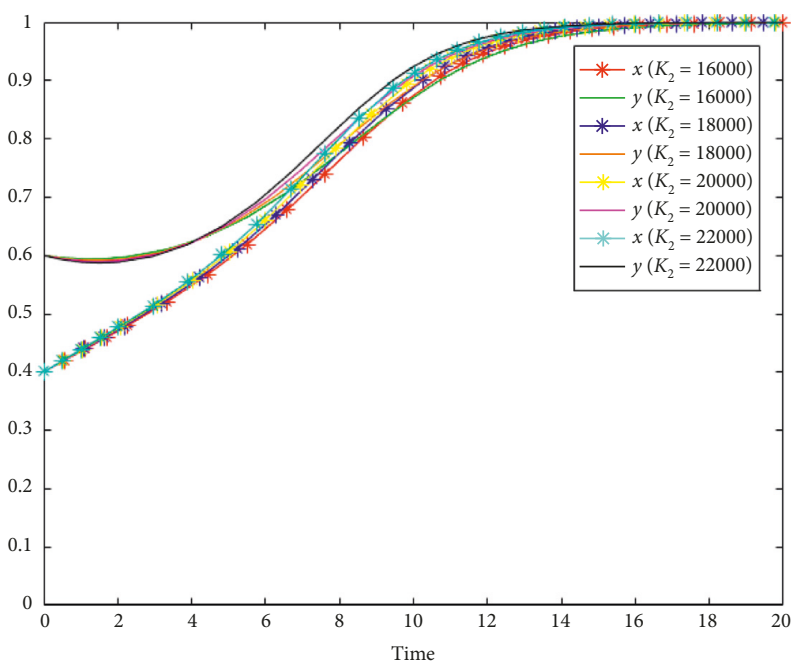

(j)

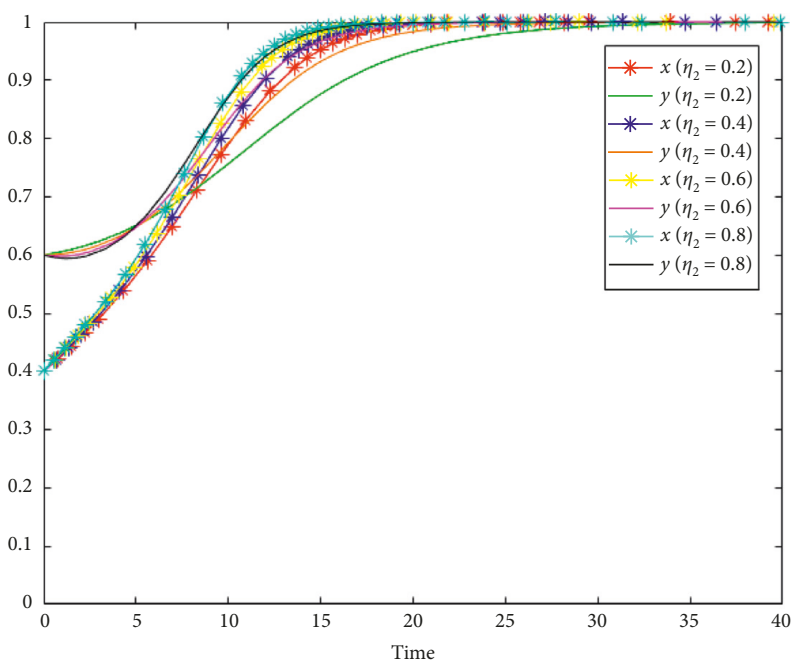

(l)

FIGURE 5: Influences of the evolutionary game model parameters. Influence of (a) parameter $\mu_{1}$, (b) parameter $\mu_{2}$, (c) parameter $\alpha_{1}$, (d) parameter $\alpha_{2}$, (e) parameter $\beta_{1}$, (f) parameter $\beta_{2}$, (g) of parameter $C_{1}$, (h) parameter $C_{2}$, (i) parameter $K_{1}$, (j) parameter $K_{2}$, (k) parameter $\eta_{1}$, and (l) parameter $\eta_{2}$. 
computer simulation experiments using MATLAB. We mainly focused on the interaction behavior of knowledgesharing. Our simulation results successfully captured the interaction behaviors between two groups accurately and thus predicted the evolution tendency with respect to time. Different from the classical game model that requires absolute rationality and complete information, the evolutionary game theory relaxes the two limitations, thereby making the simulation results conform to actual situations. The simulation results reveal some valuable findings relevant to integrated project team leaders, allowing them to profoundly understand knowledge-sharing as well as how to improve overall project performance.

(1) The evolution path results show that as long as there is a game player whose knowledge-sharing cost is greater than the synergetic benefits, as shown in Figures 2(b)-2(d), both game players will eventually abandon knowledge-sharing, thereby leading to failure of cooperation. Knowledge-sharing is often regarded as a function of cost and benefit [102]. However, synergetic benefit generated from the collaboration is excluded, when analyzing the influence of benefit on knowledge-sharing behavior. This may lead to an unreliable result. Compared to prior studies, we distinguish the types of direct and synergetic benefits and demonstrate that synergetic rather than direct benefit plays a key role in knowledge-sharing.

(2) The evolutionary tendency of interaction behaviors is affected greatly by the initial proportion of choosing knowledge-sharing strategy, as shown in Figures 3 and 4 . If both game players are at moderate- or high-effort level, they will eventually choose to share knowledge with each other. Additionally, even if one game player is at low-effort level, it can be driven by the other game player being at high-effort level to adopt the "share" strategy. Thus, the game player with smaller proportion of preferring to knowledge-sharing will be positively influenced by the other game player with higher proportion of knowledge-sharing. Ultimately, both game players choose to share knowledge. However, both game players will abandon the share strategy when they are all at low-effort level. Although all kinds of critical factors, including culture environment, close relationship, trust, leadership behavior, team members attitude, intrinsic and extrinsic motivation, and so on [63, 83, 103-105] affect knowledge-sharing within project teams or organizations, however, the influence of project team members structure on strategy interaction behavior has never been discussed in prior studies. This finding fixed the knowledge gap and provides a bright insight for project team leaders to improve performance.

(3) Knowledge stock is proved an important indicator for learning organization. The real purpose of building a learning organization in the knowledge economy is to improve team members' knowledge stock [106]. However, most studies only point out the importance of knowledge stock, lacking a deeper understanding of the influences of knowledge stock on knowledge-sharing mechanism within an organization. Through simulation results, we found that knowledge stock positively promote knowledgesharing. Although Knowledge integration could increase benefit [107], however, most studies do not elaborate what kind of knowledge fusion generates benefit and its impact on knowledge-sharing behavior. The finding in this research suggests that only heterogeneous knowledge fusion brings about added benefit and reveals further that it has a positive correlation with knowledge-sharing behavior.

A great number of studies have paid attention to the role of team members' willingness in knowledgesharing behavior. However, most researchers mainly focus on how to improve willingness to share knowledge from static perspective [108], wherein the data are collected only at a point of time. And, thus exploring dynamically the relationship between team members' willingness and evolutionary trend of knowledge-sharing behavior is absent. We get out of this dilemma and successfully reveal that degree of knowledge-sharing positively affects knowledge-sharing from the dynamic perspective. The concept of knowledge absorption capacity, defined as the ability to identify, digest, and utilize knowledge in the external environment, is believed to affect company's competitive advantages greatly [109]. However, most researchers only study it at the organizational level, lacking an explanation of influence of knowledge absorption capacity on knowledge-sharing behavior. We introduce this concept at the individual level and explore the relationship between them and found that knowledge absorption capacity has a positive correlation with knowledge-sharing behavior within project team.

Synergetic management is regarded as an important part and provides a theoretical fundament for organizations to improve management efficiency through information sharing and complementary cooperation [110]. Based on the extant literature, however, influence of synergetic effect on knowledge-sharing is rarely involved, which is a knowledge gap need to address. Through our numerical simulation results, we found that raising the value of synergetic effect coefficient can improve the probability of knowledge-sharing under certain restrictions. The convergence rate depends on the size of the parameters. That is, the larger the values of the parameter are, the faster the interaction behavior converges to the combined "share, share" strategy.

(4) The knowledge-sharing cost coefficient plays a negative role in promoting knowledge-sharing. The simulation results, as shown in Figures 5(g) and 5(h), 
indicate that with the increase of the knowledgesharing cost coefficient, the evolution rate of interaction behavior converging to 1 slows down and moves away from the combined strategy "share, share." When the value of the knowledge-sharing cost coefficient reaches a certain level, the evolution trend reverses. Then, the larger the cost coefficient is, the faster the evolution results converge to 0 . That is, both game players will increasingly give up their motivation for knowledge-sharing, thereby exhibiting passive non-cooperative attitude. By comparison of the simulation results of the parameters above, we observe that a small variation in the parameter of the knowledge-sharing cost coefficient will change the evolutionary direction, for example, when $C_{1}$ increases from 0.04 to 0.05 , and the evolution results converge from the combined strategy "share, share" to the combined strategy "not share, not share". That is, the two game players abandon knowledge-sharing, leading to the death of cooperation. Therefore, it can be concluded that the evolutionary tendency of the interaction behavior is most sensitive to the parameter of knowledge-sharing cost coefficient. Despite analysis of influences of cost on knowledgesharing behavior in prior studies, to our best knowledge, very few studies assess the degree of importance of cost in knowledge management field. This is a very important problem need to addressed, because it can help project managers allocate reasonable resources to improve performance within the project team and reduce unnecessary waste. Our research work can fix this knowledge gap and provide valuable guidance for project manager to understand deeply the key role of cost in knowledge management.

\section{Conclusion and Implications}

The IPD method is an emerging research domain that has received extensive attention from stakeholders in the AEC industry. Our goal is to study knowledge-sharing strategies and the evolutionary trend of strategic interaction among integrated project team members. An innovative model, which takes benefits and costs into consideration, is established by taking advantage of the evolutionary game theory to capture the dynamic behavior of knowledgesharing and thus reveal the cooperation tendency among game players. Moreover, simulation experiments are carried to verify the results derived from the theoretical analysis to study the influence of model variables on the evolution trend of interaction behavior. Our research findings indicate that the knowledge stock, heterogeneous knowledge proportion, degree of knowledge-sharing, knowledge absorption coefficient, and synergetic effect coefficient all contribute to knowledge-sharing. A strong negative correlation was found between knowledge-sharing cost coefficient and strategy interaction. From the theoretical analysis and simulation results, we propose that the following implications can be obtained for integrated project managers to improve the cooperation and overall project performance.

(1) For the integrated project managers, the priority is to make sure the knowledge-sharing cost is not greater than the indirect benefits, or it will directly lead to a failure of cooperation. Further, the cost-control ability should be improved, because the evolution result is most affected by the parameter $C_{i}$ according to the numerical simulation outcome. In terms of present application, most completed integrated projects lack a dynamic monitoring mechanism of cost, leading to low efficiency of cost control. Specifically, due to the defects of traditional construction technology, dynamic monitoring cannot fully cover the construction project, resulting in the lack of a cost control plan. This adversely affects project management and even delays the progress of the whole project. The real-time cost control needs to be based on a big data model that includes quantity of information at all stages of the project. As an emerging technology, BIM can act as an information-integrated platform to satisfy the information requirements of the cost dynamical control. Therefore, perfect cost dynamic monitoring mechanism, combined with BIM technology, should be established for the project manager, so as to improve the cost-control ability.

(2) Party selection for IPD is important for the owner. According to the simulation results, we now know that improving the parameters of the knowledge stock, heterogeneous knowledge proportion, and knowledge absorption coefficient will promote the knowledge-sharing between both game players. Therefore, the owner should consider the stakeholders' experience of implementing IPD projects to ensure they have rich knowledge stock. Further, it is important to investigate whether the stakeholders have operated different types of projects so as to ensure significant knowledge difference among them. Knowledge absorption capability is closely related to stakeholders' characteristics. Based on the theory of learning organizations, compared with traditional organizations, the team members in learning organization have better learning ability and knowledge absorption ability. Learning organizations are an important feature for a successful enterprise and has been increasingly by all walks of life. Therefore, the owner should develop an index system set to judge and select the stakeholders who have the optimal knowledge absorption capability.

(3) More attention should be paid to knowledge-sharing willingness, as it plays a positive role in promoting knowledge-sharing. For project managers, it is essential to establish rights and a liability distribution mechanism in order to further arouse the intrinsic motivation of each project team member. According the current practice of IPD, serious lack of trust- 
based relationship and inappropriate rewards hinder the willingness for knowledge-sharing among stakeholders. Hence, the project manager should speed up the development of trust and incentive mechanisms to remove these barriers.

(4) Synergetic capability building is another important work for the project managers. As discussed in Section 4.1, the synergetic coefficient is subject to three factors: synergy organization, synergy culture, and synergy technology. Project managers, in synergy organization aspect, should carry out broad business process reengineering to adjust to the requirements of IPD and BIM. This would allow free flow of information and knowledge within the project team. Regarding synergy culture, project managers should convene coordination meetings to align goals, motivation, and the ideal of value and thus eliminate conflicts caused by cultural differences among different stakeholders. Finally, regarding synergy technology, project managers should require stakeholders to adopt a building information platform that supports the open information standards, e.g., Industry Foundation Class (IFC), to meet the requirements of information exchange throughout the life cycle of a project. The synergetic effect can be improved through these measures.

Nevertheless, there are some limitations to this study that should be investigated in the follow-up research. First, the data of projects adopting IPD are difficult to obtain. Hence, our findings were mainly derived through numerical simulation. This may neglect some actual and valuable information that is difficult to obtain in literature reviews. In future research work, an empirical analysis could be conducted to further supplement the research results. Second, we did not consider the risk factors in the evolutionary game model, because the risks vary greatly depending on the types of projects. Thus, we seek to investigate the risk types in detail and establish a risk knowledge base to offer more valuable suggestions.

Despite these limitations in this study, our research findings still have important contributions in both theory and practice. Theoretically, our research work can provide the evolutionary mechanism behind knowledge-sharing strategies and broaden our understanding of relationship between project performance and knowledge-sharing. Practically, we offer valuable references for integrated project team leaders to broaden their understandings of how cooperation is influenced by different factor and thus taking corresponding measures to improve project team performance.

\section{Data Availability}

The data used to support the findings of this study are included within the article.

\section{Conflicts of Interest}

The authors declare that they have no conflicts of interest.

\section{Acknowledgments}

The authors appreciate those experts who assisted them in the semistructured interviews and also gratefully acknowledge the experts for their constructive comments and suggestions. This work was supported by the "Fundamental Research Funds for the Central Universities” (DUT18JC44).

\section{References}

[1] H. A. Mesa, K. R. Molenaar, and L. F. Alarcón, "Exploring performance of the integrated project delivery process on complex building projects," International Journal of Project Management, vol. 34, no. 7, pp. 1089-1101, 2016.

[2] D. R. Hale, P. P. Shrestha, G. E. Gibson, and G. C. Migliaccio, "Empirical comparison of design/build and design/bid/build project delivery methods," Journal of Construction Engineering and Management, vol. 135, no. 7, pp. 579-587, 2009.

[3] W. A. Lichtig, "The integrated agreement on project performance," Construction Lawyer, vol. 26, no. 3, pp. 1-8, 2006.

[4] P. Mitropoulos and C. B. Tatum, "Management-driven integration," Journal of Management in Engineering, vol. 16, no. 1 , pp. $48-58,2000$.

[5] D. J. Kelly, Investigating the Relationships of Project Performance Measures with the Use of Building Information Modeling (BIM) and Integrated Project Delivery (IPD), Eastern Michigan University, Ypsilanti, MI, USA, 2015.

[6] B. Zareie and N. J. Navimipour, "The effect of electronic learning systems on the employee's commitment," International Journal of Management Education, vol. 14, no. 2, pp. 167-175, 2016.

[7] Z. Soltani and N. J. Navimipour, "Customer relationship management mechanisms: a systematic review of the state of the art literature and recommendations for future research," Computers in Human Behavior, vol. 61, pp. 667$688,2016$.

[8] M. Alvesson, "Social identity and the problem of loyalty in knowledge-intensive companies," Journal of Management Studies, vol. 37, no. 8, pp. 1101-1124, 2010.

[9] N. J. Navimipour, A. M. Rahmani, A. H. Navin, and M. Hosseinzadeh, "Expert cloud: a cloud-based framework to share the knowledge and skills of human resources," Computers in Human Behavior, vol. 46, pp. 57-74, 2015.

[10] X. Zhang, P. O. D. Pablos, and Z. Zhou, "Effect of knowledge sharing visibility on incentive-based relationship in electronic knowledge management systems: an empirical investigation," Computers in Human Behavior, vol. 29, no. 2, pp. 307-313, 2013.

[11] E. Ochieng and L. Hughes, "Managing project complexity in construction projects: the way forward," Architectural Engineering Technology, vol. 2, no. 1, pp. 1-2, 2013.

[12] K. I. Gidado, "Project complexity: the focal point of construction production planning," Construction Management and Economics, vol. 14, no. 3, pp. 213-225, 1996.

[13] A. L. Aryani, M. Suzila, K. Narimah, and M. S. Fathi, "Building information modeling (BIM) application in Malaysian construction industry," International Journal of Construction Engineering and Management, vol. 2, no. 4, pp. 1-6, 2013.

[14] W. S. Matthew, "Project alliancing: a relational contracting mechanism for dynamic projects," Lean Construction Journal, vol. 2, no. 1, 2005. 
[15] C. Thomsen and J. Darrington, Managing Integrated Project Delivery, Construction Management Association of America (CMAA), McLean, VA, USA, 2010.

[16] D. C. Kent and B. Becerik-Gerber, "Understanding construction industry experience and attitudes toward integrated project delivery," Journal of Construction Engineering and Management, vol. 136, no. 8, pp. 815-825, 2010.

[17] O. Mathhews and G. A. Howell, "An integrated project delivery: an example of relational contracting," Lean Construction Journal, vol. 2, no. 1, pp. 46-61, 2005.

[18] AIA (American Institute of Architects), IPD Case Studies, University of Minnesota, Minneapolis, MN, USA, 2012.

[19] S. M. Allameh, J. K. Pool, A. Jaberi, and F. M. Soveini, "Developing a model for examining the effect of tacit and explicit knowledge-sharing on organizational performance based on EFQM approach," Journal of Science and Technology Policy Management, vol. 5, no. 3, pp. 265-280, 2014.

[20] J. Liebowitz and I. Megbolugbe, "A set of frameworks to aid the project manager in conceptualizing and implementing knowledge management initiatives," International Journal of Project Management, vol. 21, no. 3, pp. 189-198, 2003.

[21] Z. Ma, D. Zhang, and J. Li, "A dedicated collaboration platform for integrated project delivery," Automation in Construction, vol. 86, pp. 199-209, 2018.

[22] C. Y. Chang, W. J. Pan, and R. Howard, "Impact of building information modeling implementation on the acceptance of integrated delivery systems: structural equation modeling analysis," Journal of Construction Engineering and Management, vol. 143, no. 8, article 04017044, 2017.

[23] J. Ma, Z. Ma, and J. Li, "An IPD-based incentive mechanism to eliminate change orders in construction projects in China," KSCE Journal of Civil Engineering, vol. 21, no. 7, pp. 2538-2550, 2017.

[24] Q. Wu, A Research on the Influencing Path of Trust on Management Performance of Integrated Project Delivery Team, Tianjin University, Tianjin, China, 2012.

[25] A. S. Hanna, "Benchmark performance metrics for integrated project delivery," Journal of Construction Engineering and Management, vol. 142, no. 9, article 04016040, 2016.

[26] G. Radaelli, M. Mura, N. Spiller, and E. Lettieri, "Intellectual capital and knowledge sharing: the mediating role of organisational knowledge-sharing climate," Knowledge Management Research \& Practice, vol. 9, no. 4, pp. 342-352, 2011.

[27] M. Polanyi, "Tacit knowing: its bearing on some problems of philosophy," Review of Modern Physics, vol. 34, no. 4, pp. 601-615, 1962.

[28] J.-H. Woo, M. J. Clayton, R. E. Johnson, B. E. Flores, and C. Ellis, "Dynamic knowledge map: reusing experts' tacit knowledge in the AEC industry," Automation in Construction, vol. 13, no. 2, pp. 203-207, 2004.

[29] G. Anand, P. T. Ward, and M. V. Tatikonda, "Role of explicit and tacit knowledge in six sigma projects: an empirical examination of differential project success," Journal of Operations Management, vol. 28, no. 4, pp. 303-315, 2010.

[30] M. T. Hansen, N. Nohria, and T. Tierney, "What's your strategy for managing knowledge?," Harvard Business Review, vol. 77, no. 2, p. 106, 1999.

[31] P. K. Couchman and L. Fulop, "Examining partner experience in cross-sector collaborative projects focused on the commercialization of R\&D," Innovation: Organization \& Management, vol. 11, no. 1, pp. 85-103, 2009.
[32] I. Nonaka, "A dynamic theory of organizational knowledge creation," Organization Science, vol. 5, no. 1, pp. 14-37, 1994.

[33] Z. Wu, Z. Zhong, W. Liu, W. Zhang, and X. Yao, "Construction of multi-layer semantic database based on mpeg-7," Computer Science, vol. 39, pp. 532-535, 2012.

[34] S. Fernie, S. D. Green, S. J. Weller, and R. Newcombe, "Knowledge sharing: context, confusion and controversy," International Journal of Project Management, vol. 21, no. 3, pp. 177-187, 2003.

[35] P. Hendriks, "Why share knowledge? The influence of ICT on the motivation for knowledge sharing," Knowledge and process management, vol. 6, no. 2, pp. 91-100, 1999.

[36] R. R. A. Issa and J. Haddad, "Perceptions of the impacts of organizational culture and information technology on knowledge sharing in construction," Construction Innovation, vol. 8, no. 3, pp. 182-201, 2008.

[37] J. N. Cummings, "Work groups, structural diversity, and knowledge sharing in a global organization," Management Science, vol. 50, no. 3, pp. 352-364, 2004.

[38] N. J. Navimipour and Y. Charband, "Knowledge-sharing mechanism and techniques in project teams: literature review, current trends," Computers in Human Behavior, vol. 62, pp. 730-742, 2016.

[39] J. V. Annadatha, Sociocultural Factors and Knowledgesharing Behaviors in Virtual Project Teams, Robert Mirris University, Moon, PA, USA, 2012.

[40] F. Farajpour, M. T. Taghavifard, and A. Yousefli, "Information sharing assessment in supply chain: hierarchical fuzzy rule-based system," Journal of Information \& Knowledge Management, vol. 17, no. 1, article 1850002, 2018.

[41] N. Khatri, G. D. Brown, and L. L. Hicks, "From a blame culture to a just culture in health care," Health Care Management Review, vol. 34, no. 4, pp. 312-322, 2009.

[42] M. Chiregi and N. J. Navimipour, "A new method for trust and reputation evaluation in the cloud environments using the recommendations of opinion leaders' entities and removing the effect of troll entities," Computers in Human Behavior, vol. 60, pp. 280-292, 2016.

[43] M. Yuan, X. Zhang, Z. Chen, D. R. Vogel, and X. Chu, "Antecedents of coordination effectiveness of software developer dyads from interacting teams: an empirical investigation," IEEE Transactions on Engineering Management, vol. 56, no. 3, pp. 494-507, 2009.

[44] L. Y. Zhang and J. He, "Critical factors affecting tacitknowledge-sharing within the integrated project team," Journal of Management in Engineering, vol. 32, no. 2, article 04015045, 2016.

[45] B. Zareie, N. J. Navimipour, and Y. Charband, "Knowledgesharing mechanisms and techniques in project teams: literature review, classification, and current trends," Computers in Human Behavior, vol. 62, pp. 730-742, 2016.

[46] N. J. Navimipour and B. Zareie, "A model for assessing the impact of e-learning system on employees' satisfaction," Computers in Human Behavior, vol. 53, pp. 475-485, 2015.

[47] Y. Charband and N. J. Navimipour, "Knowledge sharing mechanisms in the education," Kybernetes, vol. 47, no. 7, pp. 1456-1490, 2018.

[48] N. J. Navimipour, A. H. Navin, and A. M. Rahmani, "Behavioral modeling and automated verification of a cloud-based framework to share the knowledge and skills of human resources," Computers in Industry, vol. 68, pp. 65-77, 2015.

[49] P. Fouladi and N. J. Navimipour, "Human resources ranking in a cloud-based knowledge sharing framework using the 
quality control criteria," Kybernetes, vol. 46, no. 5, pp. 876-892, 2017.

[50] Z. H. Yang and Q. F. Shi, "Opportunity cost analysis of tacit knowledge-sharing in colleges and universities," Science and Technology Management Research, vol. 27, no. 5, pp. 234236, 2007.

[51] A. Kankanhalli, B. C. Y. Tan, and K. K. Wei, "Contributing knowledge to electronic knowledge repositories: an empirical investigation," MIS Quarterly, vol. 29, no. 1, pp. 113-143, 2005.

[52] S. Karkoulian, L. C. Messarra, and R. Mccarthy, "The intriguing art of knowledge management and its relation to learning organizations," Journal of Knowledge Management, vol. 17, no. 4, pp. 511-526, 2013.

[53] A. K. Gupta and V. Govindarajan, "Knowledge management's social dimension: lessons from nucor steel," Sloan Management Review, vol. 42, no. 1, pp. 71-80, 2000.

[54] T. J. Jewels, Motivators and Inhibitors to Knowledge-Sharing in IT Teams, Queensland University of Technology, Brisbane, Australia, 2006.

[55] L. P. Liu, "Cost, benefit and incentive mechanism of knowledge-sharing in enterprises," Commercial Research, vol. 8, pp. 98-101, 2006.

[56] N. J. Navimipour and Z. Soltani, "The impact of electronic environmental knowledge on the environmental behaviors of people," Computers in Human Behavior, vol. 55, pp. 1052-1066, 2016.

[57] P. Zhang and F. F. Ng, "Attitude toward knowledge sharing in construction teams," Industrial Management \& Data Systems, vol. 112, no. 9, pp. 1326-1347, 2012.

[58] W. Teerajetgul and C. Charoenngam, "Factors inducing knowledge creation: empirical evidence from Thai construction projects," Engineering, Construction and Architectural Management, vol. 13, no. 6, pp. 584-599, 2006.

[59] T. Cooke, "Can knowledge sharing mitigate the effect of construction project complexity?," Construction Innovation, vol. 13, no. 1, pp. 5-9, 2013.

[60] F. L. Ribeiro, "Enhancing knowledge management in construction firms," Construction Innovation, vol. 9, no. 3, pp. 268-284, 2009.

[61] B. Xia and A. P. C. Chan, "Measuring complexity for building projects: a delphi study," Engineering, Construction and Architectural Management, vol. 19, no. 1, pp. 7-24, 2012.

[62] H. S. Robinson, P. M. Carrillo, C. J. Anumba, and A. M. AlGhassani, "Knowledge management practices in large construction organisations," Engineering, Construction and Architectural Management, vol. 12, no. 5, pp. 431-445, 2005.

[63] G. D. Ni, Q. B. Cui, L. H. Sang, W. S. Wang, and D. C. Xia, "Knowledge-sharing culture, project-team interaction, and knowledge-sharing performance among project members," Journal of Management in Engineering, vol. 34, no. 2, article 04017065, 2018.

[64] I. Ruuska and M. Vartiainen, "Characteristics of knowledge sharing communities in project organizations," International Journal of Project Management, vol. 23, no. 5, pp. 374-379, 2005.

[65] H. Doloi, K. C. Iyer, and A. Sawhney, "Structural equation model for assessing impacts of contractor's performance on project success," International Journal of Project Management, vol. 29, no. 6, pp. 687-695, 2011.

[66] H. Baumgartner and C. Homburg, "Applications of structural equation modeling in marketing and consumer research: a review," International Journal of Research in Marketing, vol. 13, no. 2, pp. 139-161, 1996.

[67] N. Cliff, "Some cautions concerning the application of causal modeling methods," Multivariate Behavioral Research, vol. 18 , no. 1, pp. 115-126, 1983.

[68] R. C. MacCallum and J. T. Austin, "Applications of structural equation modeling in psychological research," Annual Review of Psychology, vol. 51, no. 1, pp. 201-226, 2000.

[69] B. Xiong, M. Skitmore, and B. Xia, "A critical review of structural equation modeling applications in construction research," Automation in Construction, vol. 49, pp. 59-70, 2015.

[70] S. J. Breckler, "Applications of covariance structure modeling in psychology: cause for concern?,” Psychological Bulletin, vol. 107 , no. 2 , pp. $260-273,1990$.

[71] K. Nusair and N. Hua, "Comparative assessment of structural equation modeling and multiple regression research methodologies: E-commerce context," Tourism Management, vol. 31, no. 3, pp. 314-324, 2010.

[72] D. K. Yoo, "Innovation: its relationships with a knowledgesharing climate and interdisciplinary knowledge integration in cross-functional project teams," in Proceedings of the Hawaii International Conference on System Science IEEE, Hawaii, USA, 2015.

[73] N. Siggel, "Persuasion with case studies," Academy of Management Journal, vol. 50, pp. 20-24, 2007.

[74] R. B. Mcevily, "Network structure and knowledge transfer: the effects of cohesion and range," Administrative Science Quarterly, vol. 48, no. 2, pp. 240-267, 2003.

[75] P. L. Luo and X. H. Yin, "Incentive framework for knowledge-sharing based on benefit game model," R\&D Management, vol. 21, no. 2, pp. 24-29, 2009.

[76] D.-F. Li, "Linear programming approach to solve intervalvalued matrix games," Omega, vol. 39, no. 6, pp. 655-666, 2011.

[77] C. Wang, L. Wang, J. Wang, S. Sun, and C. Xia, "Inferring the reputation enhances the cooperation in the public goods game on interdependent lattices," Applied Mathematics and Computation, vol. 293, pp. 18-29, 2017.

[78] Y. Chen, S. Ding, H. Zheng, Y. Zhang, and S. Yang, "Exploring diffusion strategies for mHealth promotion using evolutionary game model," Applied Mathematics and Computation, vol. 336, pp. 148-161, 2018.

[79] J. Jin, J. Zhang, and Q. H. Zhang, "Evolutionary game theory and modeling of economic behavior," De Economist, vol. 146, no. 1, pp. 59-89, 1998.

[80] D. Li, J. Ma, Z. Tian, and H. Zhu, "An evolutionary game for the diffusion of rumor in complex networks," Physica A: Statistical Mechanics and its Applications, vol. 433, pp. 51-58, 2015.

[81] D. Friedman, "Evolutionary games in economics," Econometrica, vol. 59, no. 3, pp. 637-666, 1991.

[82] D. Friedman and K. C. Fung, "International trade and the internal organization of firms: an evolutionary approach," Journal of International Economics, vol. 41, no. 2, pp. 113$137,1996$.

[83] J. H. Humphreys, Z. Ma, and L. Qi, "Knowledge sharing in Chinese construction project teams and its affecting factors: an empirical study," Chinese Management Studies, vol. 2, no. 2, pp. 97-108, 2008.

[84] B. Jones, "Integrated project delivery (IPD) for maximizing design and construction considerations regarding sustainability," Procedia Engineering, vol. 95, pp. 528-538, 2014.

[85] S. Wang and R. A. Noe, "Knowledge sharing: a review and directions for future research," Human Resource Management Review, vol. 20, no. 2, pp. 115-131, 2010. 
[86] C.-M. Chiu, M.-H. Hsu, and E. T. G. Wang, "Understanding knowledge sharing in virtual communities: an integration of social capital and social cognitive theories," Decision Support Systems, vol. 42, no. 3, pp. 1872-1888, 2006.

[87] L. Lu, K. Leung, and P. T. Koch, "Managerial knowledge sharing: the role of individual, interpersonal, and organizational factors," Management and Organization Review, vol. 2, no. 1, pp. 15-41, 2006.

[88] T. Dewett, "Linking intrinsic motivation, risk taking, and employee creativity in an R\&D environment," RઐD Management, vol. 37, no. 3, pp. 197-208, 2007.

[89] R. Eisenberger and J. Aselage, "Incremental effects of reward on experienced performance pressure: positive outcomes for intrinsic interest and creativity," Journal of Organizational Behavior, vol. 30, no. 1, pp. 95-117, 2009.

[90] M. Baer and G. R. Oldham, "The curvilinear relation between experienced creative time pressure and creativity: moderating effects of openness to experience and support for creativity," Journal of Applied Psychology, vol. 91, no. 4, pp. 963-970, 2006.

[91] Q. Huang, R. M. Davison, and J. Gu, "The impact of trust, guanxi orientation and face on the intention of Chinese employees and managers to engage in peer-to-peer tacit and explicit knowledge sharing," Information Systems Journal, vol. 21 , no. 6, pp. 557-577, 2011.

[92] J. G. Shi, L. G. Lin, and D. Z. Tang, "Knowledge-sharing incentive model of project team members based on knowledge complementary effect," Science and Technology Management Research, vol. 24, pp. 129-135, 2014.

[93] M. Wang and C. Shao, "Special knowledge sharing incentive mechanism for two clients with complementary knowledge: a principal-agent perspective," Expert Systems with Applications, vol. 39, no. 3, pp. 3153-3161, 2012.

[94] P. Lee, N. Gillespie, L. Mann, and A. Wearing, "Leadership and trust: their effect on knowledge sharing and team performance," Management Learning, vol. 41, no. 4, pp. 473-491, 2010.

[95] X. Z. Jia, G. B. Sun, and Z. R. Ye, "Knowledge complementarity and the limit to specialization: an new classical model," Journal of Technical Economics \& Management, vol. 4, p. 135, 2010.

[96] X. Z. Jia and B. Z. Ye, "Research on innovation based on knowledge complementarity: a profit model," Economy and Management, vol. 24, no. 10, pp. 33-38, 2010.

[97] Z. J. Chen and X. Liu, "Establish evaluation model for parent -subsidiary companies synergy effects," Economic Management, vol. 32, no. 10, pp. 51-56, 2010.

[98] P. V. Montoya, R. S. Zárate, and L. Á. G. Martín, "Does the technological sourcing decision matter? Evidence from Spanish panel data," R\&D Management, vol. 37, no. 2, pp. 161-172, 2007.

[99] S. X. Zeng, X. M. Xie, and C. M. Tam, "Relationship between cooperation networks and innovation performance of SMEs,” Technovation, vol. 30, no. 3, pp. 181-194, 2010.

[100] W. M. Cohen and D. A. Levinthal, "Absorptive capacity: a new perspective on learning and innovation," Strategic Learning in a Knowledge Economy, vol. 35, no. 1, pp. 39-67, 1990.

[101] V. Scuotto, M. D. Giudice, and E. G. Carayannis, "The effect of social networking sites and absorptive capacity on SMES' innovation performance," Journal of Technology Transfer, vol. 42, no. 2, pp. 409-424, 2017.

[102] T. Jewels, Motivators and Inhibitors to Knowledge Sharing in IT Project Teams, Queensland University of Technology, Brisbane, Australia, 2006.
[103] C. H. Huang and I. C. Huang, "The moderating effect of coworkers' reactions on social ties and knowledge sharing in work teams," International Journal of Learning and Intellectual Capital, vol. 6, no. 2, pp. 156-169, 2008.

[104] Z. K. Ding and F. F. Ng, "Knowledge sharing among architects in a project design team: an empirical test of theory of reasoned action in China," Chinese Management Studies, vol. 2, no. 2, pp. 130-142, 2009.

[105] L. Y. Qi, K. Y. Wang, and Z. Z. Ma, “Antecedent factors of knowledge sharing in project teams: evidence from chinese construction sector," in Proceedings of the International Conference on E-Business\& E-Government, IEEE, Guangzhou, China, May 2010.

[106] Y. Liu and K. J. Zeng, "Research on knowledge stock of learning organization based on system dynamics," Science and Technology Management Research, vol. 38, no. 13, pp. 182-191, 2018.

[107] B. P. Cozzarin and J. C. Percival, "Complementarities between organizational strategies and innovation," Economics of Innovation and New Technology, vol. 15, no. 3, pp. 195217, 2006.

[108] A. Wiewiora, B. Trigunarsyah, G. Murphy, and V. Coffey, "Organizational culture and willingness to share knowledge: a competing values perspective in Australian context," International Journal of Project Management, vol. 31, no. 8, pp. 1163-1174, 2013.

[109] A. Fosfuri and J. Tribo, "Exploring the antecedents of potential absorptive capacity and its impact on innovation performance," Omega, vol. 36, no. 2, pp. 173-187, 2008.

[110] V. D. Mathijs, "Interfirm networks in periods of technological turbulence and stability," Research Policy, vol. 43, no. 10, pp. 1666-1680, 2014. 


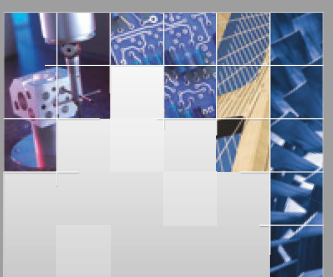

\section{Enfincering}
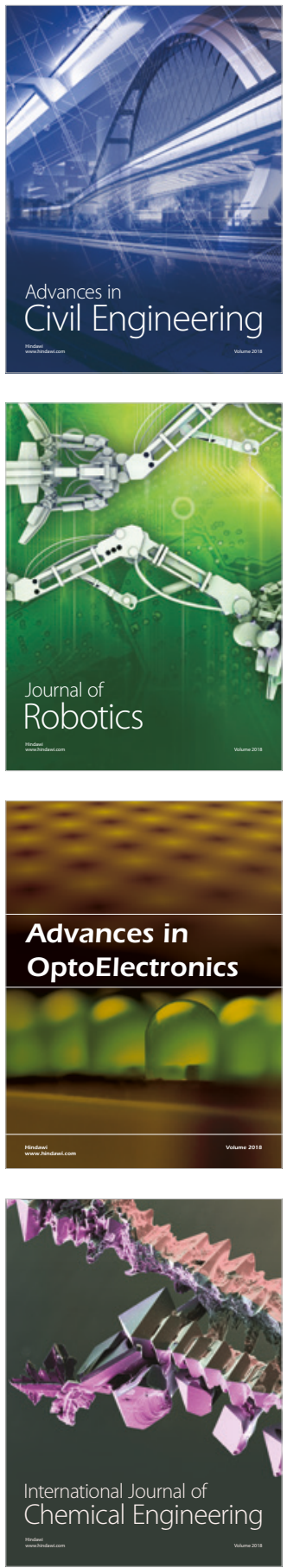

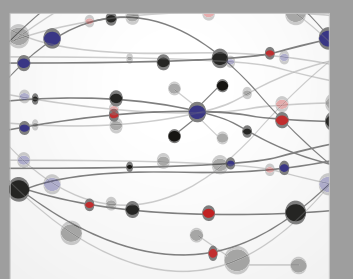

\section{Rotating \\ Machinery}

The Scientific World Journal

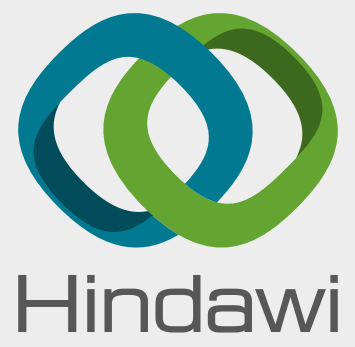

Submit your manuscripts at

www.hindawi.com
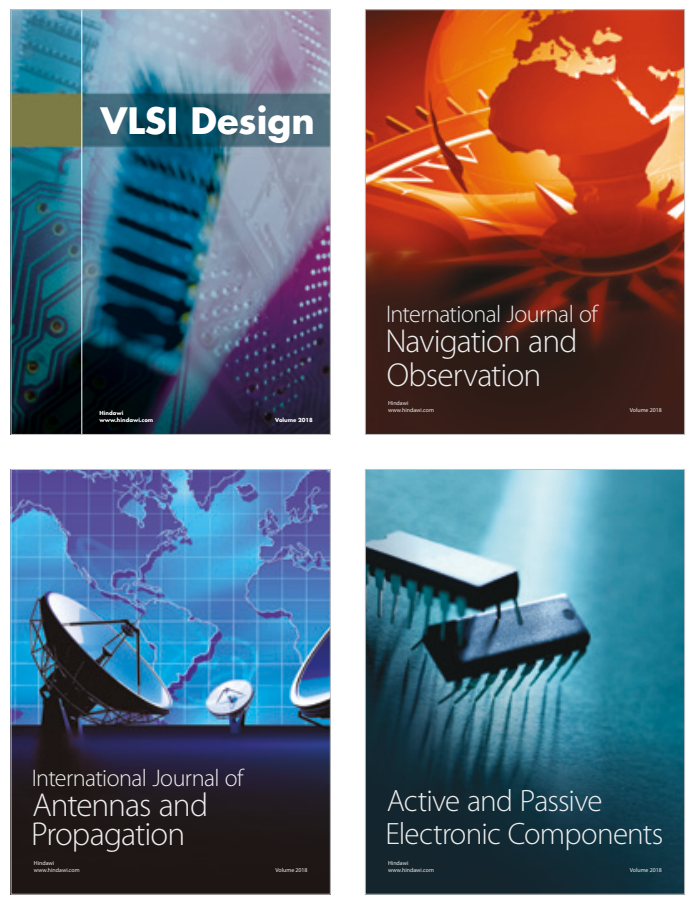
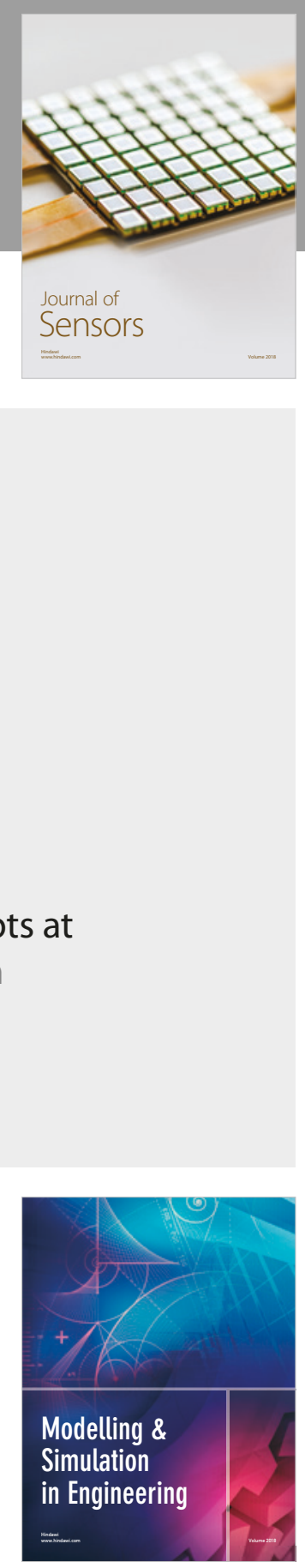

\section{Advances \\ Multimedia}
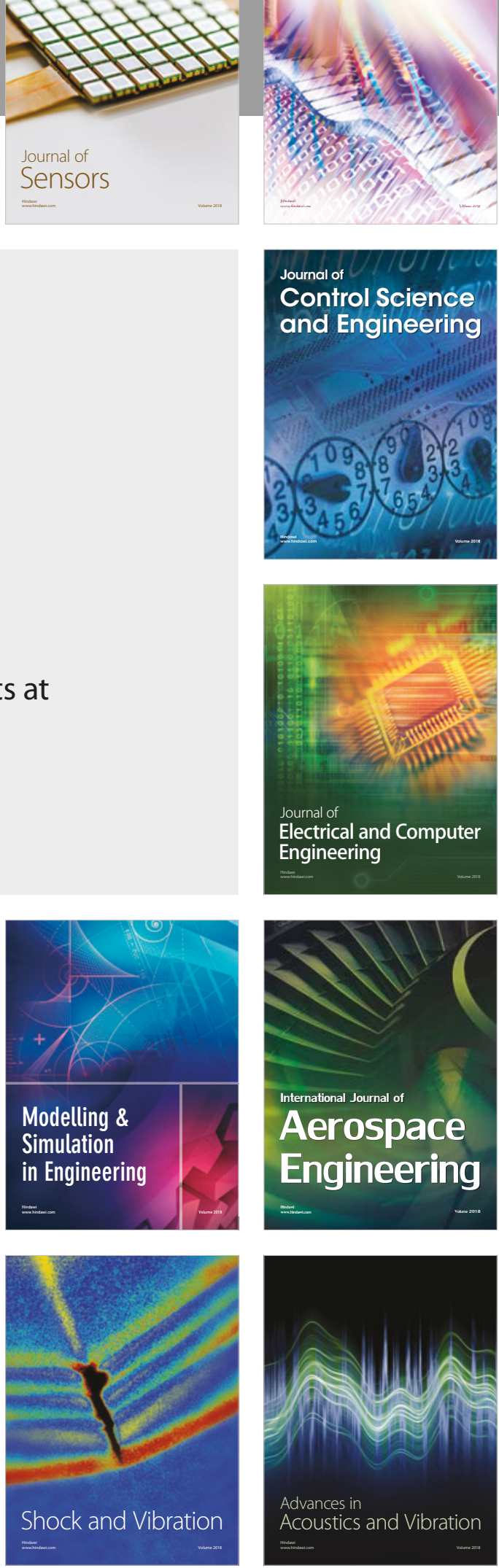